Metallurgical Transactions B, Vol. 27B, No. 4 (August), 1996, pp. 617-632.

\title{
Intermixing Model of Continuous Casting during a Grade Transition
}

\author{
Xiaoqing Huang ${ }^{\dagger}$ and Brian G. Thomas \\ Department of Mechanical and Industrial Engineering \\ University of Illinois at Urbana-Champaign \\ 1206 West Green Street \\ Urbana, IL 61801
}

\begin{abstract}
To investigate the composition distribution that develops in continuously-cast steel during a grade change, an efficient, accurate, and user-friendly computational model has been developed. The model is fully transient and consists of three submodels, which account for mixing in the tundish, mixing in the liquid core of the strand, and solidification. The first submodel of mixing in the tundish consists of two plug flow zones, two back-mixing boxes, and two dead volumes. The second submodel solves a one-dimensional diffusion equation in series with two back mixing boxes to calculate concentration histories in the strand and the third submodel transforms these histories into slab compositions. The model has been calibrated using both concentration histories measured on tundish water models and calculations from a 3-D model. It has then been verified with several sets of composition measurements along the surface and centerlines of slabs. The model is capable of tracking mixing phenomena for arbitrary tundish filling and casting speed histories. It has been used to compare the effects of different grade change procedures on the amount of intermixed steel, including standard sequence casting, flying tundish change, and insertion of grade separators. Mixing in the strand was found to be very important. Without a grade separator, a flying tundish change had very little benefit on reduced intermixing, for the typical conditions considered.
\end{abstract}

\footnotetext{
$\dagger$ Now is a technical staff member with Concurrent Technologies Corporation, Johnstown, PA 15904.
} 


\section{INTRODUCTION}

Increasing the production efficiency of the continuous casting process requires casting longer sequences of ladles without stopping and restarting the caster. As the demand for wider ranges of steel products increases at the same time, the intermixing of dissimilar grades is becoming a problem of growing concern. Steel producers need to know exactly where the mixed region exists, in order to cut out and downgrade the minimum amount of steel necessary to satisfy customer product specifications. In addition, casting conditions should be optimized to minimize the costs associated with intermixing.

Several different procedures exist to handle the casting of dissimilar grades. The easiest method is to continue casting the different grades as a single sequence. This method involves only a simple "ladle change". The process schematic in Figure 1 shows that "new" steel flowing from the next ladle will first mix with "old" steel left in the tundish. Steel then flows into the mold, where it undergoes further mixing in the long liquid pool in the strand while it solidifies. This method completely avoids losses in productivity, but produces the maximum amount of intermixed steel which needs to be downgraded. ${ }^{[1]}$ Casting conditions should be chosen to minimize the amount of intermixed steel, and / or a secondary market must be found.

The most extreme alternative is to stop the caster when the first grade is finished and to restart it with the next grade as a new sequence. This method avoids producing any intermixed steel to be downgraded. However, production time is lost to restart the caster. In addition, yield losses are incurred due to quality problems at the end and start of the cast strands. ${ }^{[2]}$

Another method, the "flying tundish change", avoids stopping the caster while preventing mixing in the tundish. The tundish is changed at the same time the ladle containing the new grade is opened, so mixing occurs only in the strand. This method is demanding on the plant operation and incurs a yield loss of the old steel remaining in the tundish, in addition to limiting the tundish life. Thus, its benefit depends on the amount of intermixed steel saved.

To further minimize intermixing, a "grade-separator" plate can be inserted into the mold. This method is capable of completely preventing mixing in the strand. ${ }^{[3]}$ However, physical insertion of the "perfect grade separator" requires significant slow down or even stoppage of strand, which incurs the risks of excessive bulging and cracks in the strand, 
breakouts, and even damaging the caster machine. In addition, the separator plates can be expensive.

As an alternative to the perfect grade-separator, a less expensive "partial grade separator" may be inserted into the liquid steel in the mold. Its large thermal mass induces solidification across the strand at a certain depth below the meniscus, which greatly limits mixing in the strand. The partial separator is easier to insert with less slow-down and risk of damage to the caster than the perfect separator. ${ }^{[3]}$

Combining the above procedures generates several different methods for handling grade transitions. Each method produces different amounts of intermixed steel and incurs different costs. In order to choose the best method for a particular operation, it is necessary to know how much intermixed steel is produced for each method. In addition, the ability to accurately predict the composition distribution in the intermixed slabs as a function of casting conditions would enable optimization of the chosen grade transition method to minimize downgrading, while avoiding the unintentional sale of intermixed product.

\section{EVENTS OF A TYPICAL GRADE TRANSITION}

During a typical "ladle change" grade transition in sequence casting, the casting speed, $\mathrm{v}_{\mathrm{c}}$, total tundish volume, $\mathrm{V}_{\mathrm{T}}$, and flow rate into the tundish, $\mathrm{Q}_{\text {in }}$, vary with time, as shown in Figure 2. Mixing begins when the new ladle is opened and the new grade of steel starts to flow into the tundish, which defines time zero. The curves at times less than zero represent events which occur prior to opening of the new ladle.

In preparation for replacement of the old ladle, the casting speed is generally decreased. This lowers the flow rates so provides more time for the transition. The extra time also allows more solidification, shortening the length of the liquid pool in the strand, thereby decreasing the mixing length. At the same time, the tundish volume decreases, particularly after the old ladle is finished. Because the tundish volume at the time of opening the new ladle almost always corresponds to the minimum tundish level, the prior drainage procedure has no effect on mixing. The amount of old grade remaining in the tundish is important, however, as lower minimum tundish volumes reduce the extent of subsequent mixing in the tundish. In the extreme case of a flying tundish change, this volume is zero.

Once the new ladle opens, the tundish refills to the desired operation level, according to the prescribed inlet flow rate and casting speed. Mixing in the tundish depends on the 
filling rate and casting speed histories, which eventually increase to reach their steady values.

After leaving the tundish, mixing occurs in the strand (unless a grade separator plate is used). Diffusion is negligible in solid steel, so the initial profile of the solidified shell, including the entire surface of the strand below the meniscus, remains completely old grade. Turbulent flow may penetrate deep within the liquid pool, however, bringing mixed steel far below the position of the meniscus at ladle open. Mixing increases towards the centerline, which solidifies last, and with increasing casting speed. Considering that the volume of liquid contained in the strand is similar to that in the drained tundish, mixing in the strand is very important.

It is clear that many events must be considered, if the composition distribution in the final slab is to be predicted accurately. Specifically, the history of tundish volume after ladle open and the entire casting speed history must be taken into account in a fully transient model, which includes mixing in both the tundish and the strand.

\section{PREVIOUS WORK}

Despite the importance of intermixing during a grade change, there does not appear to be any previous study which considers mixing in both the tundish and the strand. Several aspects of the process have been investigated separately, however. Most previous studies focus on mixing in tundishes using physical water models, ${ }^{[4-8]}$ mathematical models, ${ }^{[9-12]}$ and experimental plant measurements. ${ }^{[2,13]}$ Other work includes experimental studies of grade separators ${ }^{[3,14]}$, and a few studies of mixing in the strand. ${ }^{[1}$, $15,16]$

In previous work on mixing, ${ }^{[1]}$ the composition of the liquid can be specified as a dimensionless, or relative "concentration," C,:

$$
\mathrm{C} \equiv \frac{\mathrm{F}(\mathrm{t})-\mathrm{F}_{\text {old }}}{\mathrm{F}_{\text {new }}-\mathrm{F}_{\text {old }}}
$$

where $F(t)$ is the fraction of a given element in the alloy; $F_{\text {old }}$ and $F_{\text {new }}$ are the fractions of that element measured in the old and new grades respectively. In this definition, all concentrations range between the old grade concentration of 0 and the new grade concentration of 1 . The dimensionless concept is useful because most elements have been found to intermix equally. ${ }^{[1,16]}$ Possible exceptions to this general finding include carbon 
and aluminum, which diffuse rapidly in the solid, and might also react to form precipitates, depending on the grade.

Previous experimental investigations have focused mainly on the effects of different tundish geometries and flow control configurations on the steady flow of water through scale models of the tundish. ${ }^{[7,8,17,18]}$ Tracer injection experiments are often performed to find the plug flow time, $t_{p}$, (time when new grade first appears) and the average residence time, $t_{a}$, which is calculated from the concentration - time curves. The results are often characterized by dividing the total tundish volume into three zones: mixed volume, $\mathrm{V}_{\mathrm{m}}$, plug

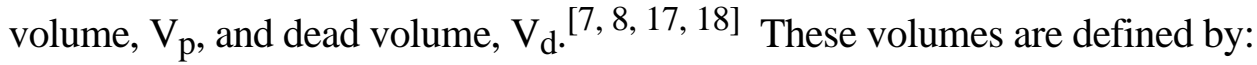

$$
\begin{aligned}
& \mathrm{V}_{\mathrm{m}}=\left(\mathrm{t}_{\mathrm{a}}-\mathrm{t}_{\mathrm{p}}\right) \mathrm{Q}_{\text {in }} \\
& \mathrm{V}_{\mathrm{p}}=\mathrm{t}_{\mathrm{p}} \mathrm{Q}_{\text {in }} \\
& \mathrm{V}_{\mathrm{d}}=\mathrm{V}_{\mathrm{T}}-\mathrm{t}_{\mathrm{a}} \mathrm{Q}_{\text {in }}
\end{aligned}
$$

Burns et al. ${ }^{[5]}$ and Mannion et al. ${ }^{[6]}$ each developed empirical models to calculate the transient concentration exiting the tundish during a grade transition, based on experimental measurements conducted with full-size water models. Their results are presented as exponential functions of time, using regression equations. The formulae and parameters vary with the specific tundish under study. It is relatively straight forward, however, to obtain good agreement between measurements and simple equations.

Finite difference models have been applied successfully by several authors to model steady-state ${ }^{[9-11]}$ and transient ${ }^{[12]}$ mixing phenomena in continuous-casting tundishes. All of these models solve the three-dimensional turbulent Navies-Stokes' equations and the mass diffusion equation. One of the critical parameters in these calculations, which controls the extent of mixing, is the effective diffusion coefficient, $\mathrm{D}_{\text {eff }}$, defined by:

$$
\mathrm{D}_{\mathrm{eff}}=\mathrm{D}_{\mathrm{o}}+\mathrm{v}_{\mathrm{t}} / \mathrm{Sc}_{\mathrm{t}}
$$

where $\mathrm{Sc}_{\mathrm{t}}$ is the turbulent Schmidt number which is generally set equal to one. This means that turbulent mass diffusion (turbulent diffusion coefficient, $\mathrm{D}_{\mathrm{t}}$ ) is the same as turbulent momentum transport (turbulent kinematic viscosity, $v_{t}$ ) and is independent of composition.

The molecular (laminar) diffusion coefficient, $\mathrm{D}_{\mathrm{O}}$, is measured for a given element diffusing through another given element, but is always negligibly small, on about the order of $10^{-8}$ $\mathrm{m}^{2} / \mathrm{s}$. This explains why the intermixing behavior of all elements is predicted to be about the same. ${ }^{[1]}$ 
Recent studies have illustrated the importance of natural convection due to thermal buoyancy on flow and mixing phenomena in tundishes. ${ }^{[4,19]}$ Thermal buoyancy in a tundish usually cannot be ignored, due to the low average flow velocity and high superheat temperatures (usually several tens of degrees). This contrasts with the liquid pool in the strand, where rapid dissipation of the superheat and strong forced convection makes thermal buoyancy negligible. ${ }^{[20]}$

Several publications describe methods to reduce mixing in the strand using a grade separator. Schmidt et al. ${ }^{[3]}$ reported on a grade separator for a slab caster at Bethlehem Steel and the corresponding measurements of Carbon, Boron, Silicon, and Phosphorous compositions along the slab centerline. Less than one meter of intermixed slab was produced with their grade separator under test conditions. Tanaka et al. ${ }^{[14]}$ describe the insertion of a physical barrier developed and used at Kawasaki Steel of Japan. A "coolant" (grade separator) was inserted into mold as part of a sequence of automated steps during the grade change, which requires $90-150$ seconds to complete.

Mixing in the strand is known to be very important, creating longer intermixed length as mold thickness and casting speed increase. ${ }^{[1]}$ Gupta et al. ${ }^{[15]}$ investigated the flow pattern and mixing characteristics in the mold region using a scale water model. The dimensionless concentration curve was found to be identical for all flow rates and fit well with a model of 2 back-mixing cells in series. Fujii et al ${ }^{[16]}$ measured composition distributions in several intermixed slabs and found negligible variation across the slab width, except very near the narrow faces.

A previous mathematical model of mixing in the strand applied a 3-D finitedifference $\mathrm{K}-\varepsilon$ turbulence model to simulate a flying tundish change, using a supercomputer. ${ }^{[1]}$ This model calculated the final composition distribution in the slab, caused by the combined effects of transient mixing in the strand and solidification during the grade change. It considered different casting conditions and the effects of transient factors, including the ramping of casting speed, and was validated with experimental measurements. ${ }^{[13]}$ The present work seeks to improve this model by adding a model of mixing in the tundish, considering the effects of a grade separator, and simplifying the strand model to execute quickly on a personal computer.

\section{OBJECTIVES}

The first objective of the present work is to develop an accurate, efficient, userfriendly, computational tool to predict the exact location of the intermixed region in continuously-cast steel slabs for any arbitrary grade transition operation and grade 
specifications. This model should be used by process engineers to optimize the standard practice for grade change operations at a given steel plant and by schedulers to design optimal casting sequences. It should also be used on-line by plant operators to specify where to cut the strand for each particular grade change.

This paper describes a mathematical model, MIX1D, which has been developed to meet this objective. The complete model consists of three separate submodels, which emulate the continuous steel casting process illustrated in Figure 1:

\section{1). Tundish mixing \\ 2). Strand mixing \\ 3). Composition in the final product (steel slab or bloom)}

The paper summarizes how each submodel has been validated or calibrated with plant measurements and briefly describes how the model has been implemented for on-line use.

The second objective of this work is to apply the model to understand the grade transition process and thereby find ways to minimize the amount of intermixed steel. As an initial step toward this goal, the paper compares the composition profiles produced using several different grade transition methods.

\section{TUNDISH MIXING MODEL}

The first submodel in this work calculates mixing in the tundish, which determines the steel composition entering into the mold and controls the surface composition of the final product. It is beyond current modeling capability to accurately model the transient mixing behavior of an arbitrary tundish without experimental calibration. Thus, a simple series of mixing boxes has been adopted, based on the three parameters: plug flow volume, mixing volume, and dead volume, which have been used successfully by previous workers to characterize the steady flow through a variety of tundish configurations. The effects of different tundish configurations on mixing at constant total volume can be represented by changing the volume fractions of these three parts. ${ }^{[7,8,17,18]}$

To account for transient effects, the present work divides each box into two components, thereby creating a total of six volume fractions, which are illustrated in Figure 3. The first three components form the first "zone" of the tundish. Flow from the ladle enters the first plug flow box. Flow then splits to enter the first dead volume and/or the first mixing box. Flow leaving the first mixing box enters the second zone of the tundish. This 
consists of a second mixing box, which exits into the second dead volume and the final plug flow box. The following sections describe the equations which are solved for each box.

\section{A. Mixing boxes}

The two mixing boxes are connected in series. Each is well-mixed, so instantly adjusts to changing inlet conditions to maintain a uniform concentration equal to its exit concentration. According to the derivation in Appendix A, the time evolution of the concentration leaving each mixing box can be found by solving:

$$
\begin{aligned}
& \frac{\mathrm{dC}_{\mathrm{m} 1}}{\mathrm{dt}}=\frac{\mathrm{Q}_{\mathrm{m} 1}}{\mathrm{~V}_{\mathrm{m} 1}}\left(\mathrm{C}_{\mathrm{p} 1}-\mathrm{C}_{\mathrm{m} 1}\right) \\
& \frac{\mathrm{d} \mathrm{C}_{\mathrm{m} 2}}{\mathrm{dt}}=\frac{\mathrm{Q}_{\mathrm{m} 2}}{\mathrm{~V}_{\mathrm{m} 2}}\left(\mathrm{C}_{\mathrm{m} 1}-\mathrm{C}_{\mathrm{m} 2}\right)
\end{aligned}
$$

The meaning of each symbol is defined in a Nomenclature section at the end of this paper.

\section{B. Plug flow boxes}

The plug flow volumes delay the passage of new grade through the tundish. They also make the eventual concentration change exiting the mold steeper with time because they consume part of the total tundish volume, thus decrease the volume available for mixing. The concentration leaving the first plug flow box, $\mathrm{C}_{\mathrm{p} 1}$, incorporates the boundary condition entering the tundish:

$$
C_{p 1}= \begin{cases}0 & \text { when } t \leq \delta t_{1} \\ C_{i n} & \text { when } t>\delta t_{1}\end{cases}
$$

This equation states that new grade from the ladle is delayed from entering the first mixing box by the time, $\delta t_{1}$. This time is calculated knowing the volume of the first plug flow zone and the flow rate history entering the tundish:

$$
\int_{\mathrm{t}-\delta \mathrm{t}_{1}}^{\mathrm{t}} \mathrm{Q}_{\mathrm{p} 1} \mathrm{dt}=\mathrm{V}_{\mathrm{p} 1}(\mathrm{t})
$$

In a similar manner, the second plug flow box delays the concentration leaving the second mixing box to enter the mold:

$$
\mathrm{C}_{\mathrm{T}}=\mathrm{C}_{\mathrm{p} 2}=\mathrm{C}_{\mathrm{m} 2}\left(\mathrm{t}-\delta \mathrm{t}_{2}\right)
$$


where the time delay, $\delta t_{2}$, is found from:

$$
\int_{\mathrm{t}-\delta \mathrm{t}_{2}}^{\mathrm{t}} \mathrm{Q}_{\mathrm{p} 2} \mathrm{dt}=\mathrm{V}_{\mathrm{p} 2}(\mathrm{t})
$$

\section{Dead volume boxes}

It is found empirically that dead zones must exist in tundishes, which reduce the effective volume available for mixing and plug flow. Two dead volume boxes are assumed in the present model to characterize these dead zones, which are illustrated as the shaded regions in Figure 3. These dead volume boxes have only an indirect effect on the mixing, which is automatically taken into account by the time-dependent volume fractions of the other boxes.

\section{Transient volumes and flow rates}

The total tundish volume, $\mathrm{V}_{\mathrm{T}}$, and the inlet flow rate, $\mathrm{Q}_{\text {in }}$ are related by satisfying the following overall mass balance on the tundish:

$$
\mathrm{Q}_{\text {in }}=\frac{\mathrm{dV}_{\mathrm{T}}}{\mathrm{dt}}+\mathrm{Q}_{\mathrm{T}}
$$

where

$$
\mathrm{Q}_{\mathrm{T}}=\mathrm{W} \mathrm{N} \mathrm{v}_{\mathrm{c}}(\mathrm{t})
$$

and $\quad \mathrm{V}_{\mathrm{T}}=\frac{\mathrm{M}_{\mathrm{T}}}{\rho}$

Because the tundish mass is easier to control and to record than its volume or inlet flow rate, the model requires pairs of tundish weight, $\mathrm{M}_{\mathrm{T}}$, versus time points as input data. The timedependent casting speed, $\mathrm{v}_{\mathrm{c}}(\mathrm{t})$, must be specified in a similar manner. Within each time interval, the model assumes a piece-wise linear variation of casting speed and a parabolic variation of tundish volume, in order to calculate $Q_{\text {in }}$ as a function of time.

The volume of each box, $\mathrm{V}_{\mathrm{i}}$, is calculated from its volume fraction and the total tundish volume:

$$
\mathrm{V}_{\mathrm{i}}=\mathrm{f}_{\mathrm{i}} \mathrm{V}_{\mathrm{T}} \quad \mathrm{i}=\mathrm{m} 1, \mathrm{~m} 2, \mathrm{p} 1, \mathrm{p} 2, \mathrm{~d} 1 \text {, and } \mathrm{d} 2
$$

Overall mass conservation requires that: 


$$
\mathrm{f}_{\mathrm{p} 1}+\mathrm{f}_{\mathrm{p} 2}+\mathrm{f}_{\mathrm{m} 1}+\mathrm{f}_{\mathrm{m} 2}+\mathrm{f}_{\mathrm{d} 1}+\mathrm{f}_{\mathrm{d} 2}=1
$$

Applying mass conservation to each box yields:

$$
\mathrm{Q}_{\mathrm{i}}=\mathrm{Q}_{\mathrm{i}, \mathrm{in}}-\frac{\mathrm{dV}_{\mathrm{i}}}{\mathrm{dt}} \quad \mathrm{i}=\mathrm{m} 1, \mathrm{~m} 2, \mathrm{p} 1, \mathrm{p} 2, \mathrm{~d} 1, \text { and } \mathrm{d} 2
$$

Integrating these equations gives the volume flow rate entering each box:

$$
\begin{aligned}
& \mathrm{Q}_{\mathrm{p} 1}=\mathrm{Q}_{\text {in }} \\
& \mathrm{Q}_{\mathrm{i}}=\mathrm{Q}_{\mathrm{i}-1}-\left(\mathrm{Q}_{\mathrm{in}}-\mathrm{Q}_{\mathrm{T}}\right) \mathrm{f}_{\mathrm{i}}-\mathrm{V}_{\mathrm{T}} \frac{\mathrm{df} \mathrm{f}_{\mathrm{i}}}{\mathrm{dt}} \quad \mathrm{i}=\mathrm{m} 1, \mathrm{~m} 2, \mathrm{p} 2
\end{aligned}
$$

where $\mathrm{df}_{\mathrm{i}} / \mathrm{dt}$ is calculated numerically given the variation of $\mathrm{f}_{\mathrm{i}}$ with time, and assuming a piece-wise linear variation of $f_{i}$ over each time interval. The initial values of these volume fractions must be input to the model, based on empirical matching with experiments.

To generalize the model to handle arbitrary time-variation of the total tundish volume, with no additional calibration with experiments, the volume fractions were adjusted with time. The procedure is based on the assumption that the total plug volume fraction, total mixing volume fraction, and total dead volume fraction each remains constant with time. The proportioning of each fraction between its two component boxes in the first and second tundish zones changes with time in order to reasonably account for changes in tundish volume. Specifically, tundish volume increases are assumed to add volume only to the boxes in the first tundish zone, while decreases take volume away only from the boxes in the second zone.

For example, during a continuous increase in total tundish volume, the volume fraction of each box in the second zone is decreased in order to maintain its original volume:

$$
\begin{aligned}
& \mathrm{f}_{\mathrm{p} 2}(\mathrm{t})=\frac{\mathrm{V}_{\mathrm{T}}(\mathrm{t}=0)}{\mathrm{V}_{\mathrm{T}}} \mathrm{f}_{\mathrm{p} 2}(\mathrm{t}=0) \\
& \mathrm{f}_{\mathrm{m} 2}(\mathrm{t})=\frac{\mathrm{V}_{\mathrm{T}}(\mathrm{t}=0)}{\mathrm{V}_{\mathrm{T}}} \mathrm{f}_{\mathrm{m} 2}(\mathrm{t}=0)
\end{aligned}
$$

The volume fraction of the corresponding box in the first zone increases, in order to satisfy the condition of constant total plug flow and constant total mixing volume:

$$
f_{p 1}(t)=f_{p 1}(t=0)+f_{p 2}(t=0)-f_{p 2}(t)
$$




$$
\mathrm{f}_{\mathrm{m} 1}(\mathrm{t})=\mathrm{f}_{\mathrm{m} 1}(\mathrm{t}=0)+\mathrm{f}_{\mathrm{m} 2}(\mathrm{t}=0)-\mathrm{f}_{\mathrm{m} 2}(\mathrm{t})
$$

Considering that the dead volumes act together and the volume fractions are constrained by Eq. [16], there are only four independent empirical constants needed for this model to simulate a given tundish under arbitrary filling conditions.

\section{E. Initial and boundary conditions}

Initial conditions are required to specify that each tundish volume contains only old grade at the time the new ladle is opened:

$$
\mathrm{C}_{\mathrm{i}}(\mathrm{t}=0)=0 \quad \mathrm{i}=\mathrm{m} 1, \mathrm{~m} 2, \mathrm{p} 1, \mathrm{p} 2, \mathrm{~d} 1 \text {, and } \mathrm{d} 2
$$

The boundary condition on concentration entering the tundish specifies that flow from the new ladle is only new grade.

$$
\mathrm{C}_{\text {in }}(\mathrm{t} \geq 0)=1
$$

\section{F. Solution Procedure}

A fourth order Rung-Kutta time integration method is used to solve the first order ordinary differential equations, Eqs. [6] and [7], together with the conditions specified in Eqs. [8 - 25]. About 500 to 800 seconds of the casting process must be simulated before the concentration out of the tundish reaches steady state. This takes about 200 time steps. Table I shows that this requires very little computer resources.

\section{STRAND MIXING MODEL}

The concentration entering the mold cavity as a function of time significantly affects

the composition distribution in the final product. ${ }^{[1]}$ The second submodel considers mixing in the strand, by dividing the strand into three zones, as depicted in Figure 4. These include two well-mixed zones in the upper mold region and a diffusion zone in the lower portion of the liquid pool until the metallurgical length. A mixing box approximation is again used to simulate the upper zones and a one-dimensional finite-difference diffusion equation is solved in the lower zone.

\section{A. Upper-strand mixing boxes}

To incorporate the strong turbulent flow and mixing in the upper portion of the liquid pool, this region is simplified into two fully-mixed volumes, linked together in series. 
The concentration is thus governed by the following equations, similar to those employed in the tundish model:

$$
\begin{aligned}
& \frac{\mathrm{dC}_{\mathrm{s} 1}}{\mathrm{dt}}=\frac{\mathrm{Q}_{\mathrm{s} 1}}{\mathrm{~V}_{\mathrm{s} 1}}\left(\mathrm{C}_{\mathrm{T}}-\mathrm{C}_{\mathrm{s} 1}\right) \\
& \frac{\mathrm{dC}_{\mathrm{s} 2}}{\mathrm{dt}}=\frac{\mathrm{Q}_{\mathrm{s} 2}}{\mathrm{~V}_{\mathrm{s} 2}}\left(\mathrm{C}_{\mathrm{s} 1}-\mathrm{C}_{\mathrm{s} 2}\right)
\end{aligned}
$$

The concentration entering the first box from the tundish, $\mathrm{C}_{\mathrm{T}}$, is obtained from the tundish mixing model described in the previous section. For a flying tundish change, $\mathrm{C}_{\mathrm{T}}$ is simply set to one, representing new grade.

At ladle open, each box contains only new grade, which defines the initial condition:

$$
\mathrm{C}_{\mathrm{s} 1}(\mathrm{t}=0)=\mathrm{C}_{\mathrm{s} 2}(\mathrm{t}=0)=0
$$

The volume of each box roughly corresponds to the recirculating volumes in the upper and lower recirculation zones, observed in steel casters with bifurcated submerged entry nozzles.

$$
\begin{aligned}
& \mathrm{V}_{\mathrm{s} 1}=\mathrm{NW} \mathrm{Z} \mathrm{Z}_{\mathrm{s} 1} \\
& \mathrm{~V}_{\mathrm{s} 2}=\mathrm{NW} \mathrm{Z} \mathrm{Z}_{\mathrm{s} 2}
\end{aligned}
$$

In the above equations, $\mathrm{Z}_{\mathrm{s} 1}$ and $\mathrm{Z}_{\mathrm{s} 2}$ denote the lengths specified for each mixing zone, determined empirically.

The flow rate through each box is calculated simply by:

$$
\mathrm{Q}_{\mathrm{s} 1}=\mathrm{Q}_{\mathrm{s} 2}=\mathrm{Q}_{\mathrm{s}}=\mathrm{NW} \mathrm{v}_{\mathrm{c}}(\mathrm{t})
$$

A fourth order Rung-Kutta method, is used again to solve the equations [26] to [31]. About 200 time steps are usually needed to simulate 1800 seconds of casting process. The small computer requirements, shown in Table I, represent a tiny fraction of those required by the 3-D model ${ }^{[1]}$, even though similar results are achieved.

\section{B. Lower strand diffusion model}

Flow leaving the second mixing box of the upper strand enters into the lower strand, which comprises the third zone of the strand mixing submodel. In this zone, the steel is moving downward at a uniform speed. Further mixing occurs due to turbulent diffusion while the steel remains liquid. Macrosegregation may also occur, but is ignored in the 
present model, which assumes all segregation to occur on a microscale only. Thus, a onedimensional transient mass-transfer equation is solved for the time-dependent concentration, $\mathrm{C}_{\mathrm{s} 3}$, between the end of the second mixing box and the end of the liquid pool:

$$
\frac{\partial \mathrm{C}_{\mathrm{s} 3}}{\partial \mathrm{t}}+\mathrm{v}_{\mathrm{z}} \frac{\partial \mathrm{C}_{\mathrm{s} 3}}{\partial \mathrm{z}}=\mathrm{D}_{\mathrm{eff}} \frac{\partial^{2} \mathrm{C}_{\mathrm{s} 3}}{\partial \mathrm{z}^{2}} \quad \text { for } \mathrm{Z}_{\mathrm{s} 1}+\mathrm{Z}_{\mathrm{s} 2}<\mathrm{z} \leq \mathrm{Z}_{\mathrm{met}}
$$

The effective diffusion coefficient, $\mathrm{D}_{\mathrm{eff}}$, in the above equation is usually dominated by its turbulent component, $v_{t} / S c$, as described in the discussion of Equation [5]. $D_{\text {eff }}$ as well as the fluid flow velocity, $\mathrm{v}_{\mathrm{Z}}$, are calculated using empirical relations given in Appendix B. In the above equation, $Z_{\text {met }}$ is the "metallurgical length," which generally extends to about $20-40 \mathrm{~m}$ below the meniscus. Its position is defined by the end of the liquid pool, described in the next section. The outlet condition imposed here is always old grade:

$$
\begin{array}{ll}
\mathrm{C}_{\mathrm{s} 3}(\mathrm{t})=0 & , \mathrm{z}>\mathrm{Z}_{\text {met }} \\
\frac{\partial \mathrm{C}_{\mathrm{S} 3}}{\partial \mathrm{z}}=0 & , \mathrm{z}=\mathrm{Z}_{\text {met }}
\end{array}
$$

The inlet concentration is the outlet from the second mixing box:

$$
\mathrm{C}_{\mathrm{s} 3}(\mathrm{t})=\mathrm{C}_{\mathrm{s} 2}(\mathrm{t}) \quad, \mathrm{z}=\mathrm{Z}_{\mathrm{s} 1}+\mathrm{Z}_{\mathrm{s} 2}
$$

and the initial condition is old grade,

$$
\mathrm{C}_{\mathrm{s} 3}(\mathrm{t}=0)=0
$$

Equations [32] to [36] are discretized using an upwinding scheme in spatial coordinates and a backwards Eulerian formula in time. The resultant finite-difference equations are solved with a TDMA (tri-diagonal matrix algorithm). To accurately simulate 1800 seconds of casting requires 210 spatial nodes, about 200 time steps, and a modest amount of computation resources, as shown in Table I.

\section{Modeling a Grade Separator}

Inserting a grade separator into the strand requires modifications to both the upper and lower zones of the strand mixing model. For a perfect grade separator, concentration in the strand is simply calculated as a plug flow with a inlet concentration equated to $\mathrm{C}_{\mathrm{T}}$. For a partial grade separator, the model assumes that diffusion and mixing are completely prevented below a specified distance, $Z_{\mathrm{r}}$, below the meniscus. This distance, which corresponds to the initial position of the grade separator, moves down the strand at the casting speed. Below $Z_{r}$, the concentration is set to zero. Above $Z_{r}$, mixing proceeds as 
usual. To achieve this, the volumes of the mixing boxes are adjusted to grow with time, in proportion to the casting speed history, according to the following equations:

$\mathrm{V}_{\mathrm{s} 1}=(\mathrm{N} \mathrm{W}) \min \left(\mathrm{Z}_{\mathrm{s} 1} ; \mathrm{Z}_{\mathrm{r}}+\mathrm{Z}_{\mathrm{t}}\right)$

$V_{\mathrm{s} 2}=\left\{\begin{array}{lr}0 & \text { for } Z_{r}+Z_{t} \leq Z_{s 1} \\ (N W) \min \left(Z_{s 2} ; Z_{r}+Z_{t}-Z_{s 1}\right) & \text { for } Z_{r}+Z_{t}>Z_{s 1}\end{array}\right.$

where $Z_{t}=\int_{0}^{t} v_{c}(t) d t$

In these equations, the volume above the grade separator is well-mixed until the grade separator moves below $\mathrm{Z}_{\mathrm{s} 1}$. The volume of the upper mixing box is then fixed, and the second box grows until the grade separator moves into the third, lower strand zone, below $\mathrm{Z}_{\mathrm{s} 1}+\mathrm{Z}_{\mathrm{s} 2}$.

The end of the lower zone is also modified:

$$
\mathrm{Z}_{\mathrm{met}}=\mathrm{Z}_{\mathrm{r}}+\mathrm{Z}_{\mathrm{t}}
$$

This equation generally stops mixing before the end of the liquid pool, according to the current position of the grade separator.

\section{MODEL OF COMPOSITION IN FINAL PRODUCT}

The last submodel calculates the composition distribution in the final steel slabs. Mixing is assumed to proceed at each point in the strand until the time when that point solidifies. To obtain the composition in the final products, $\mathrm{C}_{\mathrm{p}}$, a coordinate transformation is performed on the strand concentration histories, $\mathrm{C}_{\mathrm{i}}$, (i=s1, s2, and s3):

$$
\mathrm{C}_{\mathrm{p}}\left(\mathrm{x}_{\mathrm{p}}, \mathrm{y}_{\mathrm{p}}, \mathrm{z}_{\mathrm{p}}\right)=\mathrm{C}_{\mathrm{i}}(\mathrm{x}, \mathrm{y}, \mathrm{z}, \mathrm{t})
$$

where the spatial and time coordinates in the strand, $x, y, z$, and $t$, are related to the coordinates in the final product, $x_{p}, y_{p}, z_{p}$, through the following equations:

$$
\mathrm{x}=\mathrm{x}_{\mathrm{p}}, \quad \mathrm{y}=\mathrm{y}_{\mathrm{p},} \quad \mathrm{z}=\int_{\mathrm{t}-\mathrm{t}_{\mathrm{sh}}}^{\mathrm{t}} \mathrm{v}_{\mathrm{z}} \mathrm{dt}, \quad \mathrm{t}=\mathrm{t}_{\mathrm{sh}}-\int_{0}^{\mathrm{z}_{\mathrm{p}}} \frac{\mathrm{dz}}{\mathrm{v}_{\mathrm{z}}}
$$


In Eq. [42], $t$ represents the absolute time since opening the ladle. The other time variable, $\mathrm{t}_{\mathrm{sh}}$, denotes the solidification time of the steel shell, which corresponds to the time needed for the point under consideration in the shell to travel from meniscus to the position $\mathrm{z}$ in the strand. Because the solidification time varies with casting speed, this procedure allows the liquid pool profile, including the metallurgical length, to vary with time.

To calculate $\mathrm{t}_{\mathrm{sh}}$, a $\mathrm{kt}^{\mathrm{n}}$ relationship was assumed between shell thickness, $\mathrm{S}$, and $\mathrm{t}_{\mathrm{sh}}$ :

$$
\begin{array}{ll}
t_{s h}=\left(\frac{S}{k_{a}}\right)^{\frac{1}{n_{a}}} & S \leq S_{b} \\
t_{s h}=\left(\frac{S_{b}}{k_{a}}\right)^{\frac{1}{n_{a}}}\left(1+\frac{n_{b} S}{n_{a} S_{b}}-\frac{n_{b}}{n_{a}}\right)^{\frac{1}{n_{b}}} & S>S_{b}
\end{array}
$$

The solidification constants, $\mathrm{k}_{\mathrm{a}}, \mathrm{S}_{\mathrm{b}}, \mathrm{n}_{\mathrm{a}}$, and $\mathrm{n}_{\mathrm{b}}$, depend on spray cooling conditions at the strand surface, and the section size. This relationship allows the solidification rate to increase near the end of solidification, in order to match the known behavior found using other models and measurements. Equations [43] to [44] were chosen to ensure continuity of both shell thickness and solidification rate across the transition between the initial and final solidification regions. A typical plot of shell thickness versus time generated by this equation is given in Figure 5, based on the conditions in Table II for the Armco caster. ${ }^{[2,21]}$ Note that Eq. [44] shortens the metallurgical length considerably, relative to that calculated using Eq. [43] alone. Initial model runs, including results discussed later, were performed using $\mathrm{k}_{\mathrm{a}}=0.00327 \mathrm{~m} \mathrm{~s}^{-} .5$ and $\mathrm{S}_{\mathrm{b}}=0.1015 \mathrm{~m}$, which produces similar metallurgical lengths.

\section{MODEL VERIFICATION}

To ensure that the model can correctly approximate mixing phenomena in continuous casting machines and accurately predict composition distribution in final slabs, extensive verification and calibration was undertaken for each submodel. Specifically, the tundish submodel has been calibrated and compared using both physical water models and steel plant measurements. The strand submodel has been validated with 3-D model calculations, and the final composition submodel has been compared with measurements on slabs at several steel plants.

\section{A. Tundish Mixing Model}


The tundish mixing submodel has been calibrated and compared with measurements on full-scale water models at Armco Research Center. ${ }^{[21]}$ An example of the comparisons is given in Figure 6 for the conditions of the tundish used at Armco Butler Works. These conditions, given in Table II, include refilling the tundish from 5.1 to 10.2 tonnes in $120 \mathrm{~s}$ while the casting speed ramped back up from 0.64 to $1.0 \mathrm{~m} / \mathrm{min}$ over $300 \mathrm{~s}$. This table also includes the values of the volume fractions which were calibrated to match the concentration measurements.

The excellent agreement with these low casting speed measurements indicates that the four independent parameters in this model are sufficient to capture the mixing behavior. Without changing the parameters, the model was then applied to model different "high casting speed" conditions, (tundish refilling from 4.1 to 10.2 tonnes in 90 s at a steady casting speed of $1.13 \mathrm{~m} / \mathrm{min}$ for $1.320 \times 0.203 \mathrm{~m}$ slabs, with other conditions in Table II). Figure 6 shows that good agreement with measurements was obtained again. This implies that the model treatment of tundish mixing and refilling is reasonable. The same volume fractions were therefore used for all the simulation runs of this work.

\section{B. Strand Model}

It is very difficult to measure steel composition in the liquid pool, particularly deep in the strand. Thus, to calibrate and verify the strand submodel, the predicted concentrations were compared with those obtained using a three-dimensional, K- $\varepsilon$ turbulent flow and mass transfer model, which was developed and solved previously using finite-difference methods. ${ }^{[1]}$ The empirical constants for the lengths of the upper mixing zones, $\mathrm{Z}_{\mathrm{s} 1}$ and $\mathrm{Z}_{\mathrm{S} 2}$, were adjusted until the best fit was obtained between the two models. The optimum values were found to be $\mathrm{Z}_{\mathrm{s} 1}=\mathrm{Z}_{\mathrm{s} 2}=1.5 \mathrm{~m}$ for slabs.

The profiles of concentration versus time predicted by both models are compared in Figure 7 at the meniscus and at 3m below meniscus, for the conditions given in Table II. The simple box model always overestimates mixing initially. The discrepancies grow with distance below the meniscus, and at $3 \mathrm{~m}$ depth, the box model consistently overpredicts concentration, particularly at early times. This allows new grade to penetrate down the strand centerline deeper than it should. Overall, however, there is reasonable agreement between the two models.

A comparison of the corresponding slab compositions, seen in Figure 8, confirms that the differences between the 1-D and 3-D models are small. This suggests that the complex 3-D model can be reasonably approximated by the simple box model. Table I shows that this results in a tremendous savings in computational requirements. These 
savings allow the present model to run quickly on a personal computer, enabling easy parametric studies and on-line use at the steel plant.

\section{Slab Composition Predictions}

The model predictions of composition distribution have been found to match closely with several sets of measurements on slabs cast under a wide range of conditions during grade transitions at four different steel companies to date. These measurements include slabs cast during a flying tundish grade change at Inland Steel, ${ }^{[1,13]}$ slabs cast with a grade separator at Bethlehem Steel, ${ }^{[3]}$ and several different conditions of simple ladle changes

producing intermixed slabs cast at Armco Butler Works. ${ }^{[2,21]}$ Further discussion of some of these comparisons is reported elsewhere. ${ }^{[21,22]}$

An example comparison of the predictions of slab surface and centerline composition with plant measurements is shown in Figure 8, for the conditions of the simple ladle change given in Table II. The measurements were performed on downgraded stainless steel slabs cast at Armco Butler Works, where the Silicon contents of several samples were measured using an XRF. ${ }^{[2,21]}$ The measurements were converted to dimensionless composition according to Equation [1]. The variability observed along the centerline may be due, in part, to macrosegregation.

Figure 8 illustrates the classic composition profiles expected in the cast product after a simple ladle change grade transition. The zero point on the coordinate axis "Distance down Slab" represents the position of the meniscus at the time of opening the new ladle. Positive values denote the "old grade" region, where the steel surface was already solidified and $\mathrm{C}=0$. The surface is intermixed only after the transition point, in the negative "new grade" portion of the curve, where it roughly follows the composition entering the mold from the tundish. In contrast, the centerline has a much wider intermixing range, which penetrates deep into the old grade region. After the transition, the centerline reaches new grade faster than the surface. The concentration curves show long tails extending above the transition point at the surface and below the transition point at the center.

These observations explain why casting operations typically downgrade steel on both sides of the transition point. They also explain why measurements to ensure that grade specifications in the final product are satisfied often focus on checking centerline composition of the old grade and surface composition of the new grade.

As seen in Figure 8, very good agreement between predictions and measurements has been achieved along both the slab surface and centerline. Because the tundish mixing 
calculations had already been validated for these exact conditions, this agreement implies that the model of the strand and slab are also reasonable.

A second example of the favorable comparison between model predictions and measurements of slab composition is given in Figure 9, for the conditions of $0.215 \mathrm{~m}$ thick steel slabs cast at Bethlehem Steel with a grade separator, inserted at $0.35 \mathrm{~m}$ below the meniscus. The casting speed was decreased from $1.0 \mathrm{~m} / \mathrm{min}$ to $0.2 \mathrm{~m} / \mathrm{min}$ during the $300 \mathrm{~s}$ grade change. The measurements were conducted by Schmidt et al. ${ }^{[3]}$ along the slab centerline, for Carbon, Manganese, Aluminum and Boron alloy contents, each converted to dimensionless composition with Eq. [1].

This figure shows reasonable agreement between predictions and measurements, validating the grade separator model. The results again suggest that mixing behavior depends only on the dimensionless concentration and not on the individual element. ${ }^{[1]}$ Each element exhibits the same mixing behavior, despite its different molecular diffusion coefficient. This suggests that the turbulent diffusion coefficient dominates the mixing behavior, as assumed in the model.

\section{ON-LINE MODEL IMPLEMENTATION}

To be most useful, the model should be implemented on-line at the caster. For easy use by plant personnel, the model must be accurate, robust, fast, and have a simple userinterface, including output of the results in a usable form. This section discusses the features of the model directed toward this end.

Easy use of the model requires direct input of the measured compositions of the critical alloy elements in each grade, in addition to their specification limits. Table II includes an example of this input data for two elements. According to the most critical element(s), the model should output the two critical positions on the slab which define the intermixed region to be downgraded.

To do this, the three submodels are first executed once to determine the dimensionless composition profiles in the final product. Based on previous work that most elements intermix equally, the model next calculates the dimensionless composition specifications for each element, $\mathrm{C}_{\text {upper }}$ and $\mathrm{C}_{\text {lower }}$, according to:

$$
\mathrm{C}_{\text {lower }}=\max \left(\frac{\mathrm{F}_{\text {old min }}-\mathrm{F}_{\text {old }}}{\mathrm{F}_{\text {new }}-\mathrm{F}_{\text {old }}} ; \frac{\mathrm{F}_{\text {old max }}-\mathrm{F}_{\text {old }}}{\mathrm{F}_{\text {new }}-\mathrm{F}_{\text {old }}}\right)
$$




$$
\mathrm{C}_{\text {upper }}=\min \left(\frac{\mathrm{F}_{\text {new min }}-\mathrm{F}_{\text {old }}}{\mathrm{F}_{\text {new }}-\mathrm{F}_{\text {old }}} ; \frac{\mathrm{F}_{\text {new max }}-\mathrm{F}_{\text {old }}}{\mathrm{F}_{\text {new }}-\mathrm{F}_{\text {old }}}\right)
$$

where $\mathrm{F}_{\text {old min }}$ and $\mathrm{F}_{\text {old max }}$ are the minimum and maximum specifications of the given element in old grade; and $F_{\text {new min }}$ and $F_{\text {new max }}$ are the corresponding values in the new grade.

Searches are then performed over all of the elements, to find the critical element(s), which have the maximum $\mathrm{C}_{\text {lower }}$ (defining the old grade / intermixed boundary) and the minimum $\mathrm{C}_{\text {upper }}$ (defining the intermixed / new grade boundary). This ensures that the most stringent composition specification is satisfied, which may involve a different element for the old and new grades.

Next, the model searches along the slab composition results to find the critical distances which correspond to the maximum $\mathrm{C}_{\text {lower }}$ and the minimum $\mathrm{C}_{\text {upper }}$ compositions. Different options are possible as criteria to calculate these two axial positions. The most stringent choice is to satisfy the grade specifications throughout the slab, including both centerline and surface. This is achieved by searching for the $\mathrm{z}$ locations which match the minimum $\mathrm{C}_{\text {upper }}$ along the surface and the maximum $\mathrm{C}_{\text {lower }}$ along the centerline. Some applications might allow this requirement to relax, such as by satisfying the grade specification only at the surface or only at the centerline. Both searches then take place along the same axial line.

When the final product is rolled into thin sheets, the average composition across the thickness might be the best criterion to characterize the properties. For this option, the composition data are first averaged over the 16 simulation points across the half-thickness of the slab. Both searches are conducted along this new average axial composition profile.

Finally, the model outputs these two positions, which define the intermixed region on the slab(s). An example of the graphical output from the program is given in Figure 10, for typical process conditions, (case \#1, defined in Tables II and III). For this example, Silicon is the critical element at both boundaries. This typical grade change requires dimensionless composition specifications of greater than 0.9 for the new grade and less than 0.1 for the old grade, to be satisfied at both center and surface. The intermixed region is seen to be $10.1 \mathrm{~m}$ long, extending from $+5.3 \mathrm{~m}$ to $-4.8 \mathrm{~m}$. This corresponds to 19 tonnes of intermixed steel to downgrade. Relaxing the intermixing range to between 0.2 and 0.8 (the example $\mathrm{Cr}$ specification limits) reduces the length of intermixed steel to $8.1 \mathrm{~m}$, as measured from Figure 10. Alternatively, relaxing the intermixing criterion to apply to the 
average composition, while still satisfying the $0.1-0.9$ intermixing range, produces $6.7 \mathrm{~m}$ of intermixed steel.

To ensure accuracy and robustness, the model must be calibrated extensively with experimental data. Initial steps toward this goal were described in the previous section. Finally, computing requirements must be minimized. Specifically, the program must have memory and disk storage space that is small enough to run on a personal computer and enough speed to execute in only a few minutes of real time. As shown in Table I, this has been achieved. Only 450 KBytes of memory and less than 1 MBytes disk space are needed. About 2 seconds CPU time is needed on an SGI 4D/35 workstation for most conditions and 5 seconds with a grade separator. This corresponds to CPU times of about 1 minute and 2.5 minutes respectively on a $486-33 \mathrm{MHz}$ personal computer.

\section{COMPARISON OF GRADE TRANSITION PRACTICES}

The previous sections have described an efficient computational modeling tool for the prediction of composition distribution and the precise location of the intermixed steel, in steel slabs cast under a variety of conditions, including arbitrary section size, tundish filling history, casting speed history, with or without a flying tundish change and / or a grade separator. After reasonable validation with measurements, the model is ready for parametric studies to aid in optimizing grade transition procedures.

This section applies the model to investigate the relative importance of the tundish and grade separators on mixing phenomena in a typical slab casting machine. The casting conditions are all based on standard conditions for a typical ladle change, case \#1, which have been discussed in previous sections and are given in Tables II and III. Two different tundish conditions, (standard mixing and no tundish) are combined with three different strand mixing conditions, (standard mixing, partial mixing, and no mixing). Table III defines these 6 different grade transition procedures. The results are summarized in Figure 11 and Table IV, which compare the lengths and weights of intermixed steel produced for each case, assuming intermixing specifications between $\mathrm{C}=0.1$ and $\mathrm{C}=0.9$.

A seventh condition, the "heat boundary" is also examined. This represents the theoretical boundary between the two heats of steel that would result if there was perfect plug flow (no mixing) through both the tundish and the mold. This sharp boundary is often used as a reference point for the grade transition, as an alternative to the position of the meniscus at ladle open.

\section{A. Effect of Tundish Mixing}


The importance of mixing in the tundish on the amount of intermixed steel produced depends on the size and flow conditions in the tundish, relative to the section size and speed of the strand. For the conditions considered in this work, the relative importance of mixing in the tundish and the strand can be seen by comparing the results for cases \#1 and \#2 in Figures 11, 12, and 13.

Eliminating mixing in the tundish via a flying tundish change is seen to shift both the centerline and surface composition curves down the strand towards the old grade. This is clearly evident in Figure 12 and is echoed in the average composition profiles for cases $\# 1$ and \#2 in Figure 13. This occurs because new grade enters the strand earlier. As expected, the surface composition exhibits a sharper transition to new grade, which tends to shorten the intermixed region. At the same time, however, new grade also penetrates deeper into the old grade in the strand, which tends to lengthen the intermixed region. The net result is only a slight decrease in the amount of intermixed steel, from $6.7 \mathrm{~m}$ to $6.2 \mathrm{~m}$. This is consistent with the results in Figure 11, which show that using a flying tundish change reduces the amount of intermixed steel produced from 12.6 tonnes to 11.7 tonnes.

These results show that mixing in the strand is more important than mixing in the tundish. This finding is not surprising, considering that the typical caster modeled here contains more than 30 tonnes of liquid steel in the strand. This volume is many times greater than that of the small tundish modeled in this work, which was drained to half of its steady operating weight of only 10.2 tonnes. Figure 8 shows that the fast mixing in this small tundish allows steel exiting the tundish to reach $90 \%$ new grade within 4 minutes of opening the new ladle. This finding of the greater importance of strand mixing also applies to most operations with large tundishes, which are generally drained to contain less liquid than the strand.

The implication for casting operations with strand mixing is that reasonable efforts to increase plug flow and reduce mixing in the tundish may be equally effective in reducing intermixing as a flying tundish change. The former can be achieved by optimizing minimum tundish weight, refilling rate, and other tundish parameters, such as adding dams and weirs, as suggested by Damle and Sahai.[12] When strand mixing is dominant, however, the best operating practice to minimize intermixing is very different from that predicted from consideration of tundish mixing alone. For these operations, the suggestions of Damle and Sahai [12] may not be optimal, so further work is needed. 


\section{B. Effect of Perfect Grade Separator}

Mixing of new and old grades in the strand can be completely prevented with a perfect grade separator plate, which physically divides the strand by placing an impenetrable plate across the meniscus just before new grade enters the strand. Cases \#5 and \#6 in Figure 13 show the effect of a perfect grade separator, modeled with and without mixing in the tundish. The perfect separator naturally prevents mixing of the old grade already in the strand. Mixing in the tundish affects the slab composition on the new grade side of the zero point, however, because the old grade left in the tundish must eventually leave. As shown in Figure 11, the length of the intermixed slab is greatly reduced, relative to the corresponding case 1, with strand mixing (from 12.6 to 5.8 tonnes).

With a flying tundish change, case \#6, there is, of course, no intermixing and a sharp transition exists between old and new grades. It is interesting to note that this vertical line exactly divides the average composition curve for case \#5 into equal intermixed areas on the old and new grade sides of this line. This is required to satisfy the mass balances. Similarly, the heat boundary line, case \#7, equally divides the corresponding tundish mixing curve, case \#1. The distance between these two vertical lines, (1 $\mathrm{m}$ in Figure 13), represents the residual volume of old grade left in the tundish at ladle open, divided by the horizontal cross section area of the slab, $\mathrm{W} * \mathrm{~N}$.

\section{Effect of Partial Grade Separator}

Many casting operations use a grade separator that is imperfect. This "partial grade separator" effectively prevents mixing beyond a specified distance below the zero reference point on the slab at the time of ladle open. This also can be envisioned as inserting a perfect separator plate into the strand at that distance below meniscus. In either case, mixing in the strand is possible above the specified distance.

The effect of a partial grade separator is shown in cases \#3 and \#4 in Figures 14 and 15 , assuming an initial effective distance of $0.35 \mathrm{~m}$ below the meniscus. To isolate the effect on mixing in the strand alone, first consider the case of a flying tundish change, assumed in Figure 14. The grade separator cuts off the maximum intermixing distance from the metallurgical length of about $20 \mathrm{~m}$ to only $0.35 \mathrm{~m}$. As expected, this greatly reduces intermixing along the slab centerline. Along the slab surface, however, intermixing is increased. The net result is still a substantial (75\%) reduction in the total intermixed weight (from 12.6 to 3.2 tonnes). 
Figure 15 compares the average composition profiles obtained for partial grade separators both with and without mixing in the tundish. Tundish mixing increases the amount of intermixed steel, particularly along the surface, from 3.2 to 7.7 tonnes, as given in Figure 11. This increase (140\%) is far greater than the effect of tundish mixing without a separator, (7\% from 11.7 to 12.6 tonnes). This finding is expected, because there is so much extra old grade left in the tundish, relative to that in just the upper $0.35 \mathrm{~m}$ of the strand. The intermixed length is proportional to the total amount of old grade left above the grade separator in both the tundish and strand, so this finding applies even more strongly to large tundish operations. The implication of this finding is that tundish mixing becomes more important when a grade separator is used. Thus, optimal use of a grade separator should also employ a flying tundish change.

\section{Other Model Applications}

The model presented in this paper can be used off-line to help evaluate the economics of various grade transition procedures in order to decide whether practices, such as using a grade separator or flying tundish change, are cost-effective. The model can also be used to help schedule casting sequences in order to minimize down-grading.

Finally, the model can be used to optimize an existing grade change procedure. For example, the amount of intermixed steel can be minimized by draining the tundish and / or lowering the casting speed during the grade transition. However, the benefits have not been quantified and the optimum combination is not known. The effects of these and other important casting variables on intermixing will be the topic of a future study using MIX1D. 


\section{CONCLUSIONS}

1. An efficient and accurate mathematical model has been developed to calculate mixing in the tundish, strand, and final steel product during a grade change in the continuous casting process. The model is fully transient and can simulate the effects of arbitrary casting conditions, including section size, tundish refilling rate, casting speed history, presence of grade separators and / or flying tundish changes, and grade specifications.

2. The tundish model is relatively easy to calibrate and has been validated with experimental measurements under several conditions.

3. Model predictions of final composition distribution in the final steel slab have been validated with experimental measurements at several operating casters.

4. A fast on-line version of the model is available to run on a personal computer, with userfriendly input and output. It is currently being implemented at both Armco in Butler, PA and BHP in Newcastle, Australia. The model can be applied to design standard practices for grade change operations, to optimize the scheduling of sequences, and to predict where to cut the strand to isolate the intermixed region for changing casting conditions.

5. The relative importance of tundish mixing depends on the amount of steel in the tundish at ladle open compared with that contained in the liquid pool of the strand. For most operations, mixing in the strand is more important than mixing in the tundish.

6. A flying tundish change is best employed together with a grade separator. When no grade separator is used, a simple ladle change can be optimized, such as by lowering the tundish volume, to achieve similar savings in intermixed steel as produced by a flying tundish change.

7. A partial grade separator can greatly diminish the amount of intermixed steel, particularly along the centerline. Its benefit improves as its effective distance below the meniscus, where it prevents mixing, is decreased. Because the partial grade separator can be inserted with minimal cost and operating problems, and mixing in the strand is so important, it should be beneficial for most casting operations. 


\section{NOMENCLATURE}

C dimensionless concentration (or composition), defined by Equation [1]

$\mathrm{C}_{\mathrm{i}} \quad$ dimensionless concentration leaving a given box

$\mathrm{C}_{\text {in }}$ dimensionless concentration entering tundish from ladle

$\mathrm{C}_{\mathrm{T}}$ dimensionless concentration leaving tundish to enter mold

$D_{\text {eff }}$ effective diffusivity (liquid steel) $\left(\mathrm{m}^{2} \mathrm{~s}^{-1}\right)$

$\mathrm{F} \quad$ mass fraction of a given element

$f_{i} \quad$ volume fraction of a given box

$\mathrm{k}_{\mathrm{a}} \quad$ initial solidification constant $\left(\mathrm{m} \mathrm{s}^{\left.-\mathrm{n}_{\mathrm{a}}\right)}\right.$

$\mathrm{M}_{\mathrm{T}} \quad$ mass of tundish $(\mathrm{kg})$

$\mathrm{N} \quad$ strand thickness (across narrow face) (m)

$\mathrm{n}_{\mathrm{a}} \quad$ initial solidification exponent

$\mathrm{n}_{\mathrm{b}} \quad$ final solidification exponent

$\mathrm{Q}_{\mathrm{i}} \quad$ volume flow rate entering a given box $\left(\mathrm{m}^{3} \mathrm{~s}^{-1}\right)$

$Q_{\text {in }} \quad$ volume flow rate entering tundish from ladle $\left(\mathrm{m}^{3} \mathrm{~s}^{-1}\right)$

$\mathrm{Q}_{\mathrm{s}} \quad$ volume flow rate through the strand $\left(\mathrm{m}^{3} \mathrm{~s}^{-1}\right)$

$\mathrm{Q}_{\mathrm{T}} \quad$ volume flow rate entering leaving tundish to mold $\left(\mathrm{m}^{3} \mathrm{~s}^{-1}\right)$

$\mathrm{t}$ time since opening of new ladle (sec)

$\mathrm{t}_{\mathrm{sh}} \quad$ solidification time $(\mathrm{sec})$

$\mathrm{S} \quad$ shell thickness (m)

$\mathrm{S}_{\mathrm{b}} \quad$ shell thickness defining start of final solidification zone (m)

$\mathrm{V}_{\mathrm{i}} \quad$ volume of a given box $\left(\mathrm{m}^{3}\right)$

$\mathrm{V}_{\mathrm{T}} \quad$ total volume of tundish $\left(\mathrm{m}^{3}\right)$

$\mathrm{v}_{\mathrm{c}} \quad$ time dependent casting speed $\left(\mathrm{m} \mathrm{s}^{-1}\right)$

$\mathrm{v}_{\mathrm{cmin}}$ minimum casting speed $\left(\mathrm{m} \mathrm{s}^{-1}\right)$

W strand width (across wide face) (m)

$\mathrm{Z}_{\text {met }}$ metallurgical length (m)

$\mathrm{Z}_{\mathrm{i}} \quad$ length of a given mixing box in strand mixing model (m)

$\mathrm{Z}_{\mathrm{r}} \quad$ effective distance below meniscus in strand where partial grade separator stops diffusion $(\mathrm{m})$

$\mathrm{Z}_{\mathrm{t}} \quad$ distance traveled by strand $(\mathrm{m})$

$\mathrm{z} \quad$ distance down strand or slab (m)

$\delta$ time delay in plug flow box $(\mathrm{sec})$

$\rho \quad$ steel density $\left(\mathrm{kg} \mathrm{m}^{-3}\right)$

\section{Subscripts}

i pertaining to a given mixing box

d1 first dead flow box in tundish mixing model 
d2 second dead flow box in tundish mixing model

$\mathrm{m} 1 \quad$ first mixing box in tundish mixing model

$\mathrm{m} 2 \quad$ second mixing box in tundish mixing model

p1 first plug flow box in tundish mixing model

p2 second plug flow box in tundish mixing model

s1 first mixing zone in strand mixing model

s2 second mixing zone in strand mixing model

s3 diffusion zone in strand mixing model

\section{ACKNOWLEDGMENTS}

The authors wish to thank the steel companies: Inland Steel Corp. (East Chicago, IN), Armco Inc. (Middletown, OH), LTV Steel (Cleveland, OH) and BHP Co. Ltd. (Wallsend, Australia) for grants which made this research possible and for the provision of data, particularly by Jay Watson of Armco. This work is also supported by the National Science Foundation under grant No. MSS-8957195. Finally, thanks are due to the National Center for Supercomputer Applications at the University of Illinois for time on the Cray 2 and Cray-YMP supercomputers.

TABLE I. COMPUTING REQUIREMENTS (ON SGI 4D/35)

\begin{tabular}{|c|c|c|c|c|}
\hline & Tundish Model & $\begin{array}{c}\text { CPU Time } \\
(\mathrm{sec})\end{array}$ & $\begin{array}{c}\text { Memory } \\
\text { (KByte) }\end{array}$ & $\begin{array}{c}\text { Disk Space } \\
\text { (KByte) }\end{array}$ \\
\hline$(1)$ & $<0.2$ & 20,000 & 25,000 \\
$(2)$ & 3-D Upper Strand Model & $108,000(30 \mathrm{hrs})$ & & \\
$(3)$ & MIX1D Upper Strand Model & $<0.2$ & $<500$ & $<1,000$ \\
$(4)$ & 1-D Lower Strand Model & $<4$ & $<0.1$ & \\
$(5)$ & Slab Composition Model & $<5$ & & \\
Total & Total MIX1D Model: & $<500$ & \\
\hline
\end{tabular}


TABLE II. INPUT DATA (STANDARD LADLE CHANGE)

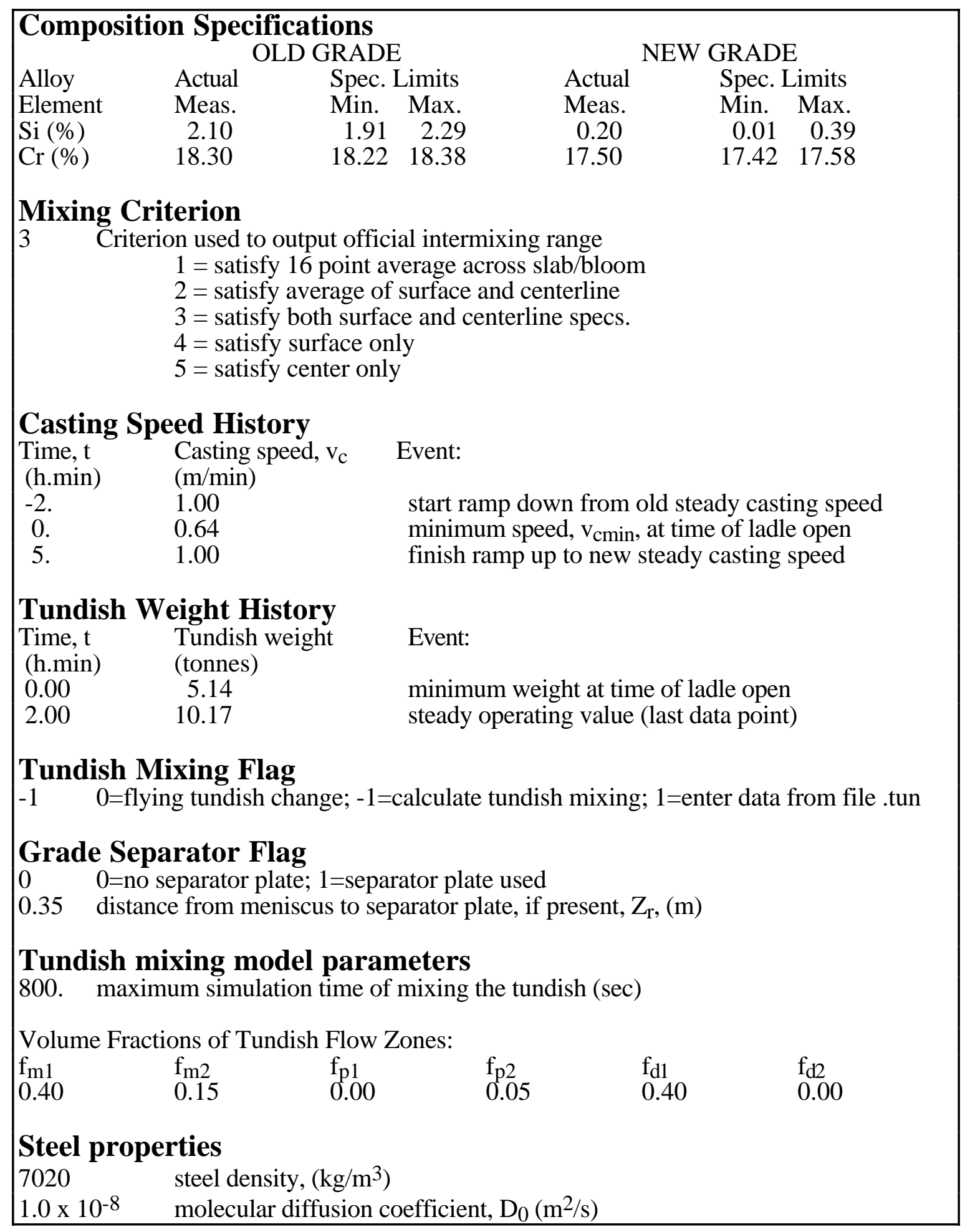




\begin{tabular}{|c|c|}
\hline Strand & ing model parameters \\
\hline & number of strands operated during the grade change \\
\hline 0.978 & slab width, W (m) \\
\hline 0.203 & slab thickness, $\mathrm{N}(\mathrm{m})$ \\
\hline $1.5,1.5$ & length of upper strand mixing boxes (m) \\
\hline 0.003 & initial solidification constant, $\mathrm{k}_{\mathrm{a}}\left(\mathrm{m} \mathrm{s}^{-\mathrm{n}_{\mathrm{a}}}\right)$ \\
\hline 0.5 & initial solidification exponent, $\mathrm{n}_{\mathrm{a}}$ \\
\hline 7.0 & final solidification exponent, $\mathrm{n}_{\mathrm{b}}$ \\
\hline 0.83 & shell thickness defining start of final solidification zone, $S_{b}(m)$ \\
\hline 0 & slab reference point $\quad(0=$ meniscus at ladle open; \\
\hline 17.0 & simulation start distance (from meniscus at ladle open) $(\mathrm{m})$ \\
\hline 37.0 & total length of slabs / blooms simulated (m) \\
\hline
\end{tabular}

TABLE III. SIMULATION CONDITIONS

\begin{tabular}{|c|c|c|c|}
\hline $\begin{array}{c}\text { Condition } \\
\#\end{array}$ & Process Conditions (Industry Name) & $\begin{array}{c}\text { Tundish } \\
\text { Condition }\end{array}$ & $\begin{array}{c}\text { Strand } \\
\text { Condition }\end{array}$ \\
\hline$\# 1$ & Standard Ladle Change & Mixing & Mixing \\
$\# 2$ & Flying Tundish Change & No Tundish & Mixing \\
$\# 3$ & Ladle Change with Separator & Mixing & Partial Mixing \\
$\# 4$ & Flying Tundish Change with Separator & No Tundish & Partial Mixing \\
$\# 5$ & Ladle Change with Perfect Separator & Mixing & No mixing \\
$\# 6$ & Flying Tundish Change with Perfect Separator & No Tundish & No mixing \\
$\# 7$ & Heat Boundary & No mixing & No mixing \\
\hline
\end{tabular}


TABLE IV. INTERMIXED MATERIALS

UNDER DIFFERENT GRADE TRANSITION METHODS

\begin{tabular}{|c|c|c|c|c|}
\hline \multirow{2}{*}{$\begin{array}{c}\text { Condition } \\
\#\end{array}$} & \multicolumn{2}{|c|}{$\begin{array}{c}\text { Based on Average Composition Across } \\
\text { Slab Thickness }\end{array}$} & \multicolumn{2}{c|}{$\begin{array}{c}\text { Based on Centerline \& Surface } \\
\text { Composition }\end{array}$} \\
\cline { 2 - 5 } & $\begin{array}{c}\text { Intermixed Slab } \\
\text { Length (m) }\end{array}$ & $\begin{array}{c}\text { Intermixed Slab } \\
\text { Weight (tonnes) }\end{array}$ & $\begin{array}{c}\text { Intermixed Slab } \\
\text { Length (m) }\end{array}$ & $\begin{array}{c}\text { Intermixed Slab } \\
\text { Weight (tonnes) }\end{array}$ \\
\hline$\# 1$ & 6.7 & 12.6 & 10.1 & 19 \\
$\# 2$ & 6.2 & 11.7 & 9.8 & 18.5 \\
$\# 3$ & 4.1 & 7.7 & 5.1 & 9.6 \\
$\# 4$ & 1.7 & 3.2 & 2.8 & 5.3 \\
$\# 5$ & 3.1 & 5.8 & 3.3 & 6.2 \\
$\# 6$ & 0 & 0 & 0 & 0 \\
\hline
\end{tabular}




\section{APPENDIX A EQUATIONS OF CONCENTRATION IN A MIXING BOX WITH CHANGEABLE VOLUME}

Considering a well-stirred, fully-mixed box shown in Figure A1, the mass balance on a given chemical species can be written as:

$$
\frac{d M}{d t}=\rho C_{\text {in }} Q_{\text {in }}-\rho C_{\text {out }} Q_{\text {out }}
$$

where $\mathrm{M}=$ the mass of the species in the box at time $t$;

$\mathrm{C}_{\mathrm{in}}=$ the concentration of the species at inlet;

$\mathrm{Q}_{\text {in }}=$ flow rate into the box;

$\mathrm{C}_{\text {out }}=$ the concentration of the species at outlet;

$\mathrm{Q}_{\text {out }}=$ flow rate out of the box.

According to the definition of flow rate, for an incompressible fluid:

$$
\frac{d M}{d t}=\frac{d}{d t}(\rho V C)=\rho V \frac{d C}{d t}+\rho C \frac{d V}{d t}
$$

where $\rho=$ the density of the mixture;

$\mathrm{C}=$ the average concentration the species in the box;

$\mathrm{V}=$ the volume of the box.

Overall mass conservation for an incompressible fluid requires that:

$$
\frac{\mathrm{dV}}{\mathrm{dt}}=\mathrm{Q}_{\text {in }}-\mathrm{Q}_{\text {out }}
$$

Combining Equations [A1] to [A3] together with the well-mixed assumption, $\mathrm{C}=\mathrm{C}_{\text {out }}$, yields the following equation for concentration in the box:

$$
\frac{\mathrm{dC}}{\mathrm{dt}}=\frac{\mathrm{Q}_{\text {in }}}{\mathrm{V}}\left(\mathrm{C}_{\mathrm{in}}-\mathrm{C}\right)
$$




\section{APPENDIX B CALCULATION OF DIFFUSION COEFFICIENT AND FLOW VELOCITY IN THE LOWER STRAND}

The effective diffusion coefficient, $\mathrm{D}_{\text {eff }}$, and the fluid flow velocity, $\mathrm{v}_{\mathrm{Z}}$, required to solve Equation [32] were defined as empirical functions of the casting speed, $v_{c}$, strand thickness, N, and strand width, W. The functions were calibrated to match the results from a 3-D turbulent, k-e turbulent flow model, which has been developed and validated with composition measurements for several casting conditions in previous work ${ }^{[1]}$. They are:

$D_{\text {eff }}= \begin{cases}\mathrm{a}_{1} & \text { for } \mathrm{Q} \leq \mathrm{Q}_{\min } \\ \frac{\mathrm{a}_{1}+\mathrm{a}_{2}}{2}+\frac{\mathrm{a}_{2}-\mathrm{a}_{1}}{2} \frac{\left(\mathrm{Q}-\mathrm{Q}_{\operatorname{mid}}\right)\left|\mathrm{Q}-\mathrm{Q}_{\operatorname{mid}}\right|^{\mathrm{a}_{3}}}{\left(\mathrm{Q}_{\max }-\mathrm{Q}_{\text {mid }}\right)^{1+\mathrm{a}_{3}}} & \text { for } \mathrm{Q}_{\min }<\mathrm{Q}<\mathrm{Q}_{\max } \\ \mathrm{a}_{2} & \text { for } \mathrm{Q} \geq \mathrm{Q}_{\max }\end{cases}$

where:

$\mathrm{Q}=\mathrm{v}_{\mathrm{c}} \mathrm{W} \mathrm{N}$, the volume flow rate of the strand, $\mathrm{m}^{3} \mathrm{~s}^{-1}$;

$\mathrm{Q}_{\min }=0.0024, \mathrm{~m}^{3} \mathrm{~s}^{-1}$

$\mathrm{Q}_{\max }=0.01, \mathrm{~m}^{3} \mathrm{~s}^{-1}$

$\mathrm{Q}_{\text {mid }}=\frac{\mathrm{Q}_{\min }+\mathrm{Q}_{\max }}{2}, \mathrm{~m}^{3} \mathrm{~s}^{-1}$

$\mathrm{a}_{1}, \mathrm{a}_{2}, \mathrm{a}_{3}=0.0042 \mathrm{~m}^{2} \mathrm{~s}^{-1}, 0.0075 \mathrm{~m}^{2} \mathrm{~s}^{-1},-0.6$ (calibration constants)

and

$$
\mathrm{v}_{\mathrm{Z}}=\mathrm{v}_{\mathrm{c}}+\mathrm{v}_{\mathrm{c}}\left(C_{\mathrm{v}}-1\right)\left(\frac{\mathrm{v}_{\mathrm{c}}-\mathrm{v}_{\mathrm{cmin}}}{\mathrm{v}_{\mathrm{cmax}}-\mathrm{v}_{\mathrm{cmin}}}\right)
$$

where: 


$$
\mathrm{C}_{\mathrm{v}}= \begin{cases}\mathrm{a}_{4} & \text { for } \frac{\mathrm{v}_{\mathrm{c}}}{\mathrm{W}^{2}} \leq \xi_{\min } \\ \mathrm{a}_{4}+\left(\mathrm{a}_{5}-\mathrm{a}_{4}\right) \frac{\left(\frac{\mathrm{v}_{\mathrm{c}}}{\mathrm{W}^{2}}-\xi_{\min }\right)^{\mathrm{a}_{6}}}{\left(\xi_{\max }-\xi_{\min }\right)^{\mathrm{a}_{6}}} & \text { for } \xi_{\min }<\frac{\mathrm{v}_{\mathrm{c}}}{\mathrm{W}^{2}}<\xi_{\max } \\ \mathrm{a}_{5} & \text { for } \frac{\mathrm{v}_{\mathrm{c}}}{\mathrm{W}^{2}} \geq \xi_{\max }\end{cases}
$$

$\mathrm{v}_{\mathrm{cmin}}=$ minimum casting speed of user-input casting speed curve, $\mathrm{m} \mathrm{s}^{-1}$;

$\mathrm{v}_{\mathrm{cmax}}=$ maximum casting speed of user-input casting speed curve, $\mathrm{m} \mathrm{s}^{-1}$;

$\xi_{\min }=0.01, \mathrm{~m}^{-1} \mathrm{~s}^{-1}$

$\xi_{\max }=0.04, \mathrm{~m}^{-1} \mathrm{~s}^{-1}$.

$\mathrm{a}_{4}, \mathrm{a}_{5}, \mathrm{a}_{6}=1.2,1.0,0.6$ (calibration constants)

It should be pointed out that the $\mathrm{Q}$ and $\mathrm{v}_{\mathrm{c}} \mathrm{W}^{-2}$ values of interest to both slab and bloom casting fall within the calibrated ranges, i.e. between $\mathrm{Q}_{\min }$ and $\mathrm{Q}_{\max }$, and between $\xi_{\min }$ and $\xi_{\max }$ respectively. 


\section{REFERENCES}

1. X. Huang and B.G. Thomas: "Modeling of Steel Grade Transition in Continuous Slab Casting Processes", Metallurgical Transactions, 1993, vol. 24B, pp. 379-393.

2. R. Sussman and J. Watson: Armco Research Center, private communication, 1993.

3. M. Schmidt and M. Ozgu: "Grade Separator and Strand Links for Uninterrupted Continuous Casting of Steel", 5th Int. Iron \& Steel Conference, Iron \& Steel Society, Inc., Washington, DC, 1986, Vol. 69, pp. 505-510.

4. M.L. Lowry and Y. Sahai: "Modeling of Thermal Effects in Liquid Steel Flow in Tundishes", 74th Steelmaking Conference Proc., The Iron and Steel Society, Inc., Warrendale, PA, 1991, Vol. 74, pp. 505-511.

5. M.T. Burns, J. Schade, W.A. Brown and K.R. Minor: "Transition Model for Armco Steel's Ashland Slab Caster", 10th Process Technology Conference, L.G. Kuhn, ed., The Iron and Steel Society, Warrendale, PA, Toronto, Ontario, Canada, 1992, Vol. 10, pp. 177-186.

6. F.J. Mannion, A. Vassilicos and J.H. Gallenstein: "Prediction of Intermix Slab Composition at Gary No. 2 Caster", 75th Steelmaking Conference Proc., L. G. Kuhn, eds., The Iron and Steel Society, Inc., Warrendale, PA, Toronto, Ontario, Canada, 1992, Vol. 10, pp. 249-254.

7. W.E. Slye, R.J. Matway and D. Samuels: "Tundish Flow Control Development in a Stainless Steel Slab Caster", 50th Electric Furnace Conference, Iron \& Steel Society, Inc., Atlanta, GA, 1992.

8. $\quad$ Y. Sahai: "Fluid Dynamics of Continuous Casting Tundish - Physical Modeling", 5th Int. Iron \& Steel Congress, Iron Steel Society, Inc., Washington, DC, 1986, Vol. 69, pp. 677-687.

9. Y. Sahai: "Computer Simulation of Melt Flow Control Due to Baffles with Hole in Continuous Casting Tundishes", Mathematical Modeling of Materials Processing Operations, J. Szekely, eds., Metallurgical Society, Inc., 1987, pp. 431.

10. M.C. Tsai and M.J. Green: "Three Dimensional Concurrent Numerical Simulation of Molten Steel Behavior and Chemical Transition at Inland Steel' s No. 2 Caster Tundish", 74th Steelmaking Conference, The Iron and Steel Society, Inc., 1991, Vol. 74, pp. 501-504.

11. O.J. Ilegbusi and J. Szekely: "The Modeling of Fluid Flow, Tracer Dispersion and Inclusion Behavior in Tundishes", Mathematical Modeling of Materials Processing Operations, J. Szekely, eds., TMS, Warrendale, PA, 1987, pp. 409.

12. C. Damle and Y. Sahai, Modeling of Grade Change Operations During Continuous Casting of Steel - Mixing in the Tundish", Trans. ISS, Vol. 22, No. 6, 1995, pp. 4959.

13. R. Gass: Inland Steel, Inc., private communication, 1992.

14. H. Tanaka, S. Shiraishi, Y. Iwanaga, S. Hiwasa, K. Orito and A. Ichihara: "Automatization of Manual Operation in the Continuous Casting Process", Steel Technical Report, 1987, (17), pp. 18-25. 
15. D. Gupta, S. Subramanian and A.K. Lahiri: "Study of Liquid Flow and Residual Time Distribution in a Continuous Slab Casting Mould", Steel Research, 1991, vol. 62 (11), pp. 496-500.

16. T. Fujii, J. Matsuno and H. Ooi: "An Analysis of Fluid Flow and Mixing Phenomena in Liquid Pool of a Continuous Casting", Tetsu-tu-Hagane, 1974, vol. 60 (7), pp. 1041-1051.

17. F. Kemeny, D.J. Harris, A. McLean, T. R. Meadowcroft, J. D. Young: "Fluid Flow Studies in the Tundish of a Slab Caster", 2nd Process Technology Conference, ISSAIME, Chicago, IL, 1981, Vol. 2, pp. 232-245.

18. E.M. Rehlaender: M. A. Sc. Thesis, University of Toronto, 1983.

19. S. Joo, R.I.L. Guthrie and C.J. Dobson: "Modeling of Heat Transfer, Fluid Flow and Inclusion Floatation in Tundishes", 74th Steelmaking Conference, The Iron and Steel Society, Inc., 1989, Vol. 72, pp. 401-411.

20. X. Huang, B.G. Thomas and F.M. Najjar: "Modeling Superheat Removal during Continuous Casting of Steel Slabs", Metallurgical Transactions B, 1992, vol. 23B, pp. 339-356.

21. J. Watson, X. Huang, and B.G. Thomas, "Steel Composition Model for Continuous Slab Casting During a Grade Transition", 52nd Electric Furnace conference, Nashville, TN, Iron and Steel Society, Inc., 1994.

22. B.G. Thomas: Unpublished Research, BHP, Report, 1994. 


\section{LIST OF FIGURES}

Figure 1. Diagram of the continuous casting process.

Figure 2. Typical changes of casting speed, tundish weight and flow rates with time.

Figure 3. Schematic of a continuous casting tundish and its six box model.

Figure 4. Schematic of three-zone strand model.

Figure 5. Shell thickness growth profile assumed in model (Table II conditions).

Figure 6. Comparison of predicted concentration exiting tundish into mold with water model measurements at Armco. [2,21]

Figure 7. Comparison of strand concentration history predicted by MIX1D with that by 3-D model. [1]

Figure 8. Comparison of predicted slab composition with measurements at Armco for a standard ladle change. [21]

Figure 9. Comparison of predicted slab composition with measurements at Bethlehem for a ladle change with partial grade separator. [3]

Figure 10. Typical output of intermixed length from MIX1D model.

Figure 11. Effect of tundish mixing and grade separator on intermixed slab length.

Figure 12. Effect of tundish mixing on slab centerline and surface composition (standard ladle change with no grade separator).

Figure 13. Effect of tundish mixing on composition averaged across slab thickness.

Figure 14. Effect of partial grade separator on slab centerline and surface composition (with a flying tundish change).

Figure 15. Effect of tundish mixing on average slab composition (with a partial grade separator). 


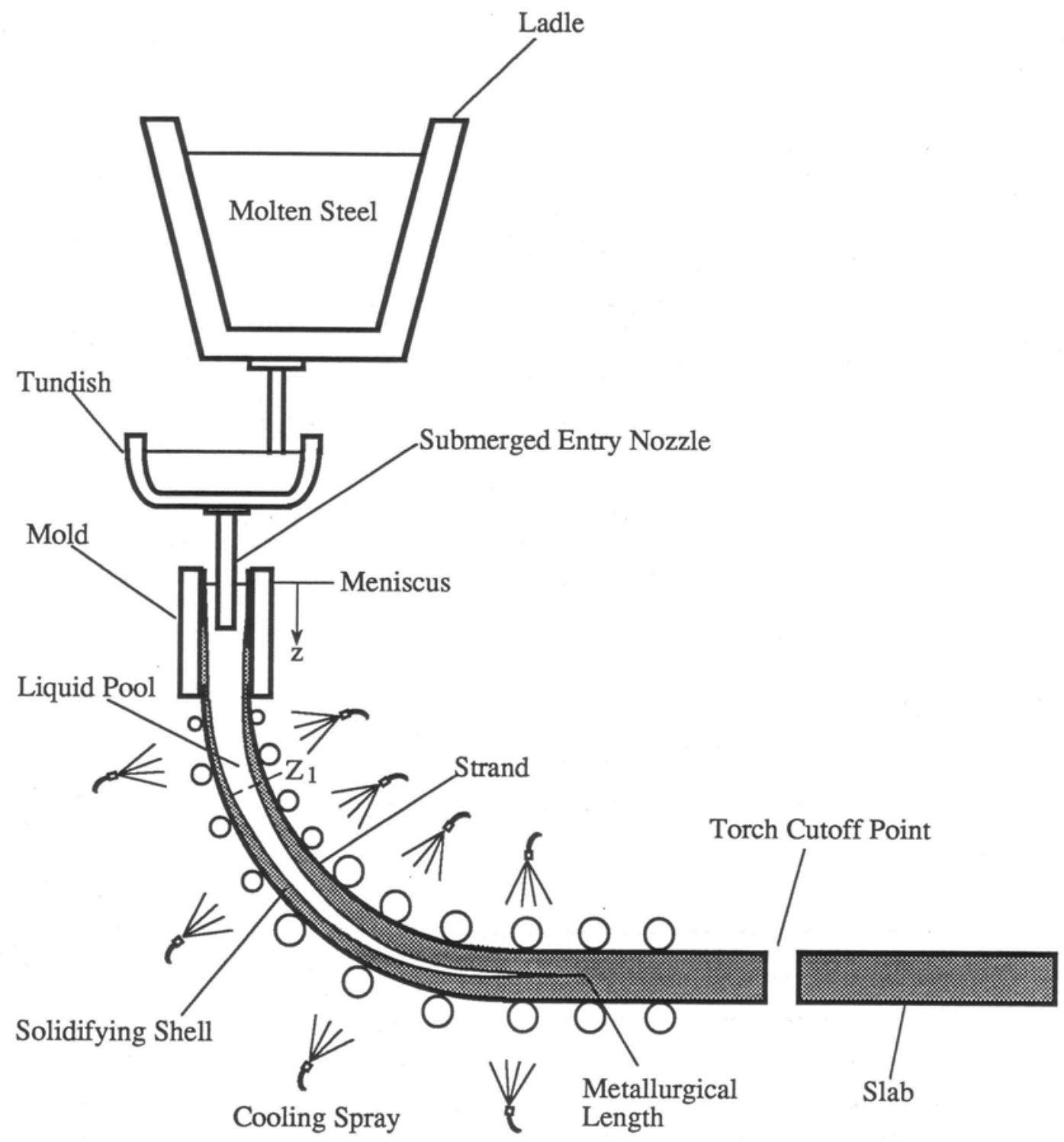

FIG. 1. Diagram of the continuous casting process. 


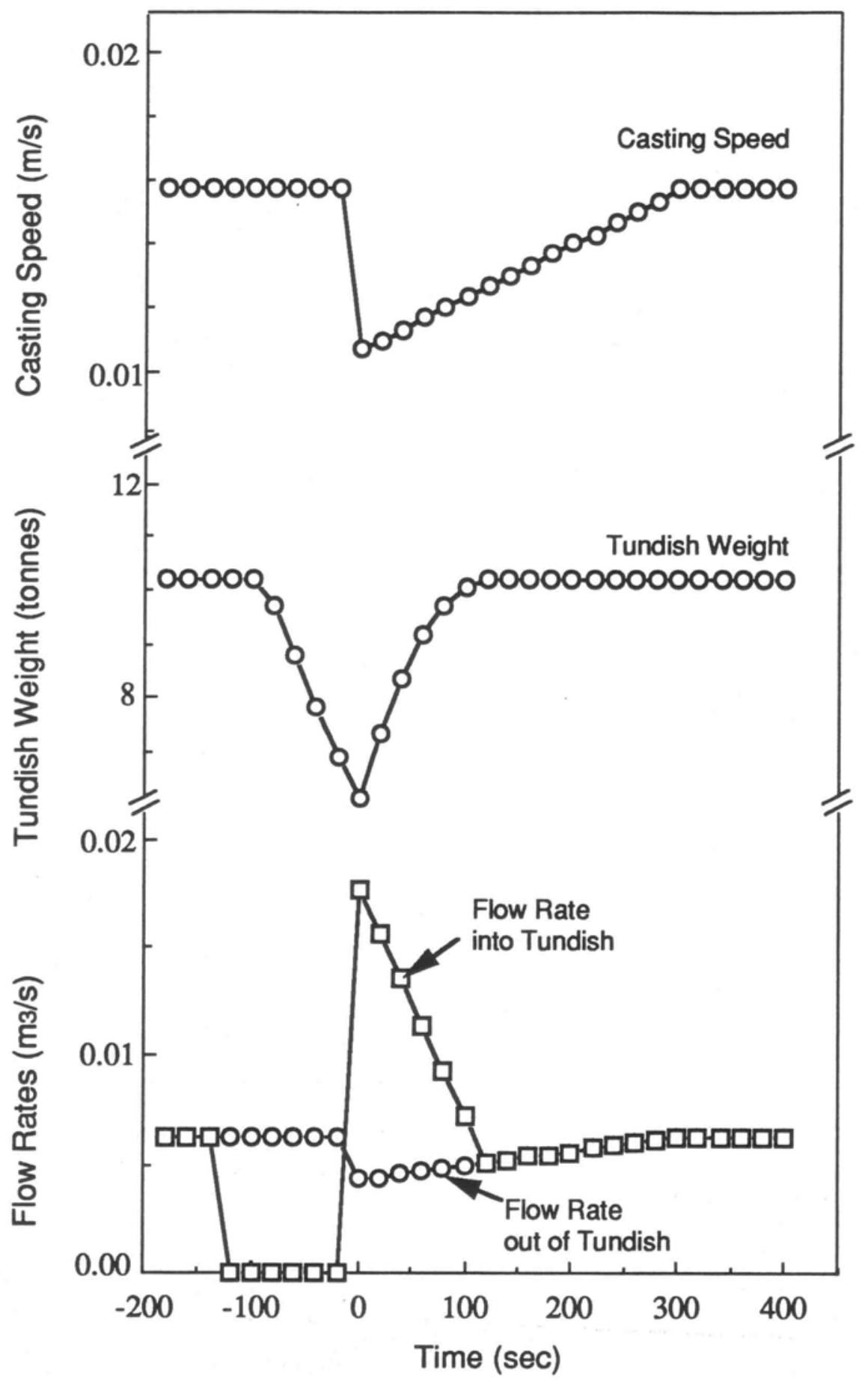

FIG. 2 Typical change of casting speed, tundish weight and flow rates with time. 

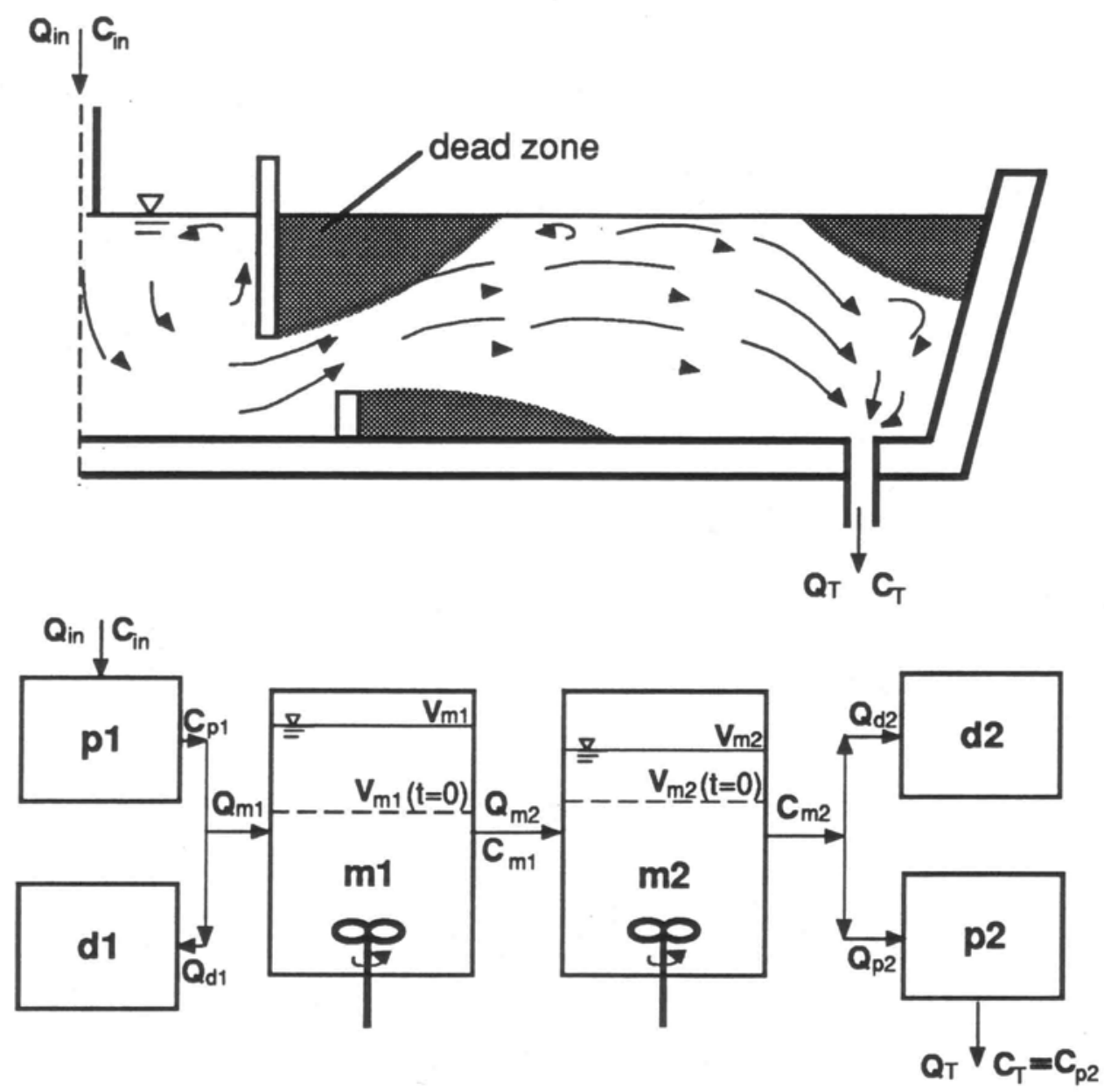

FIG. 3 Schematic of a continuous casting tundish and its six box model. 

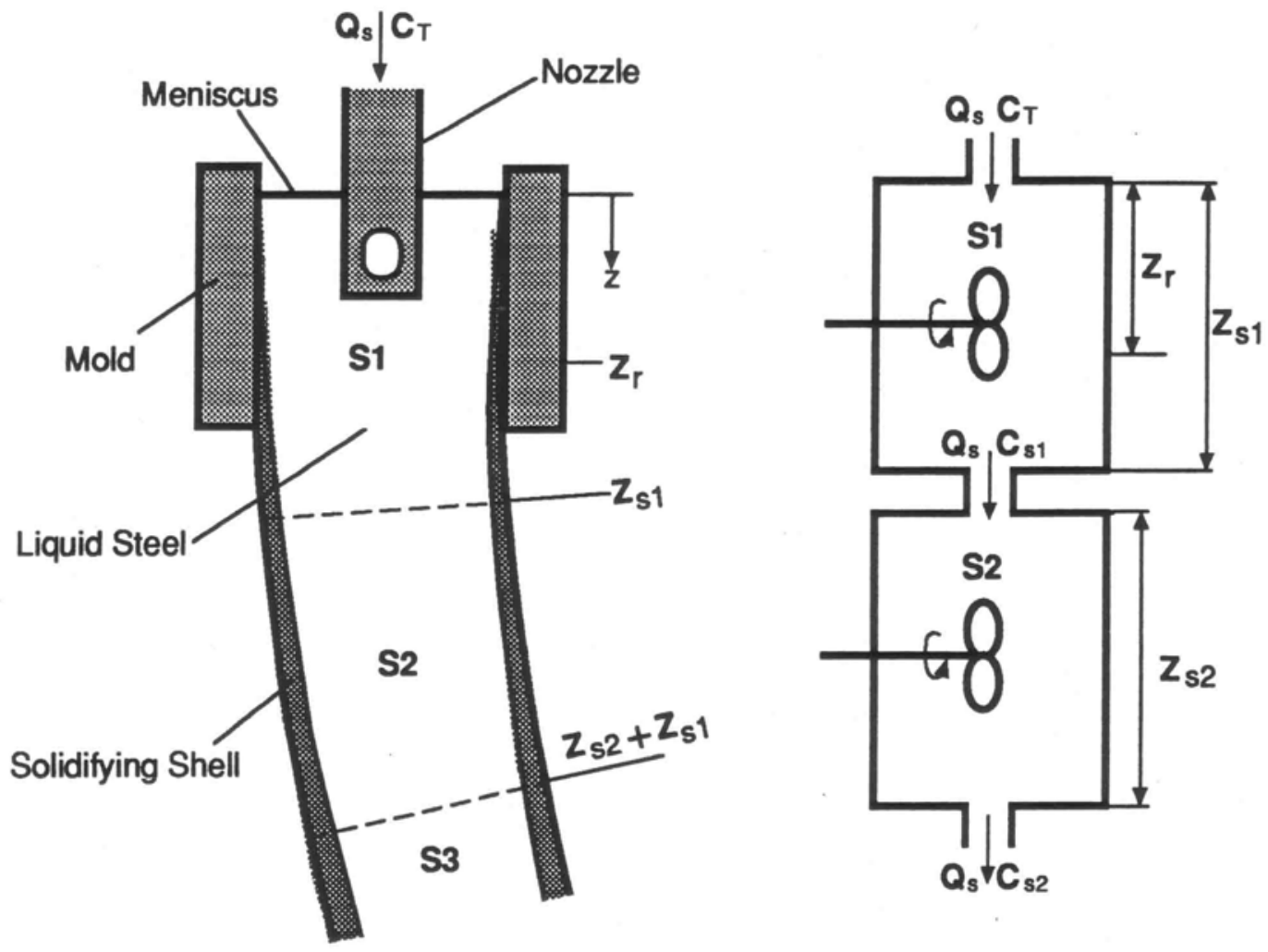

FIG. 4 Schematic of three zone strand model. 


\section{Shell thickness profile down strand}

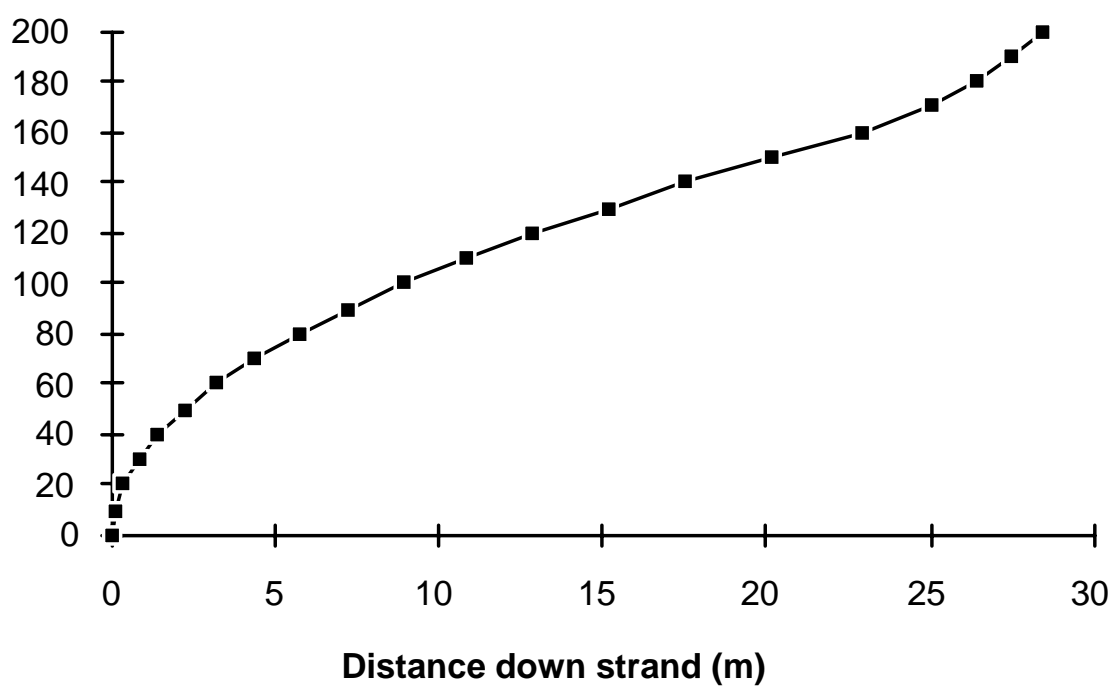

FIG. 5. Shell thickness as a function of distance below meniscus. 


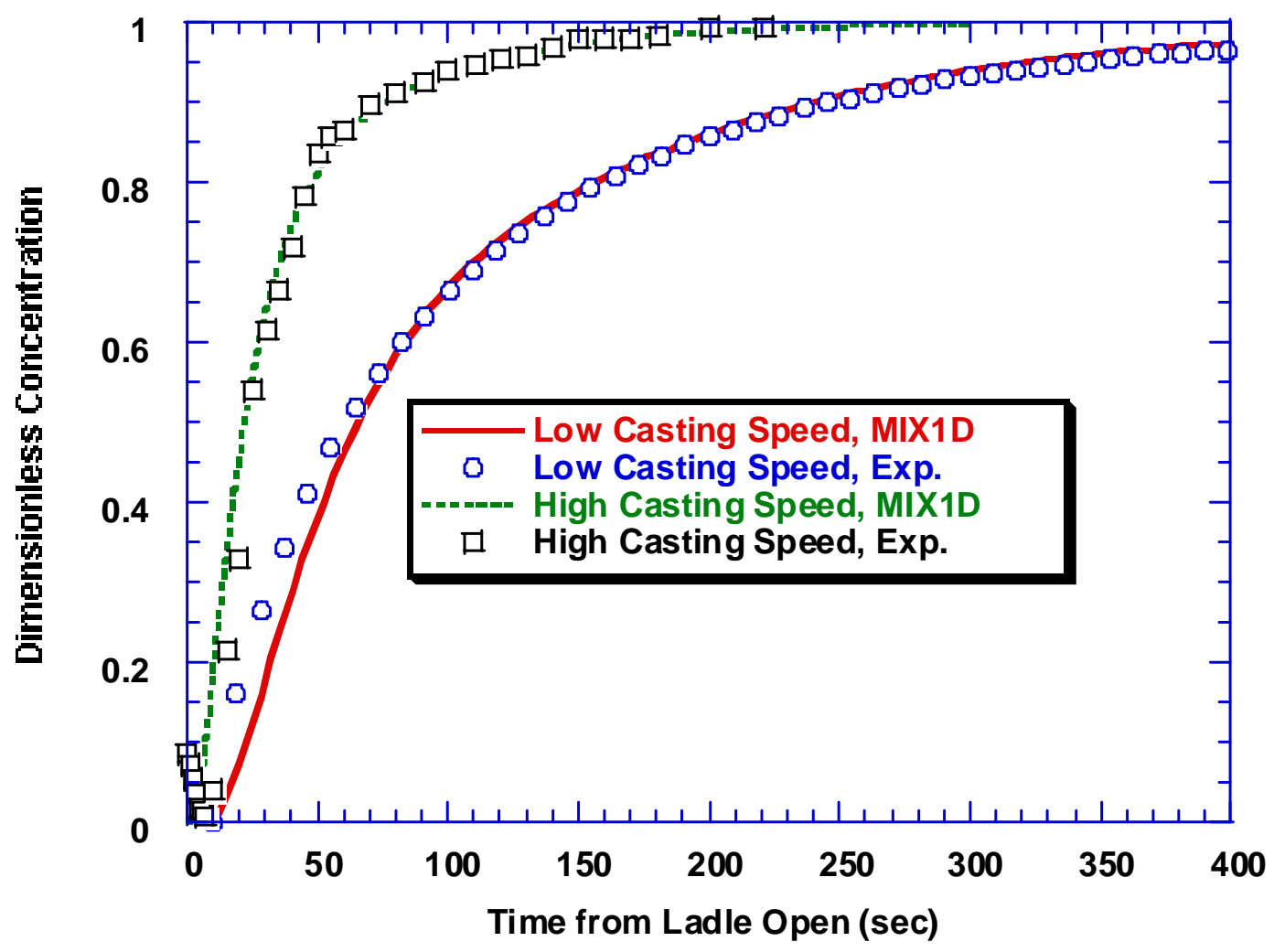

FIG. 6 Comparison of predicted dimensionless concentration existing tundish into mold with data measured at Armco. 


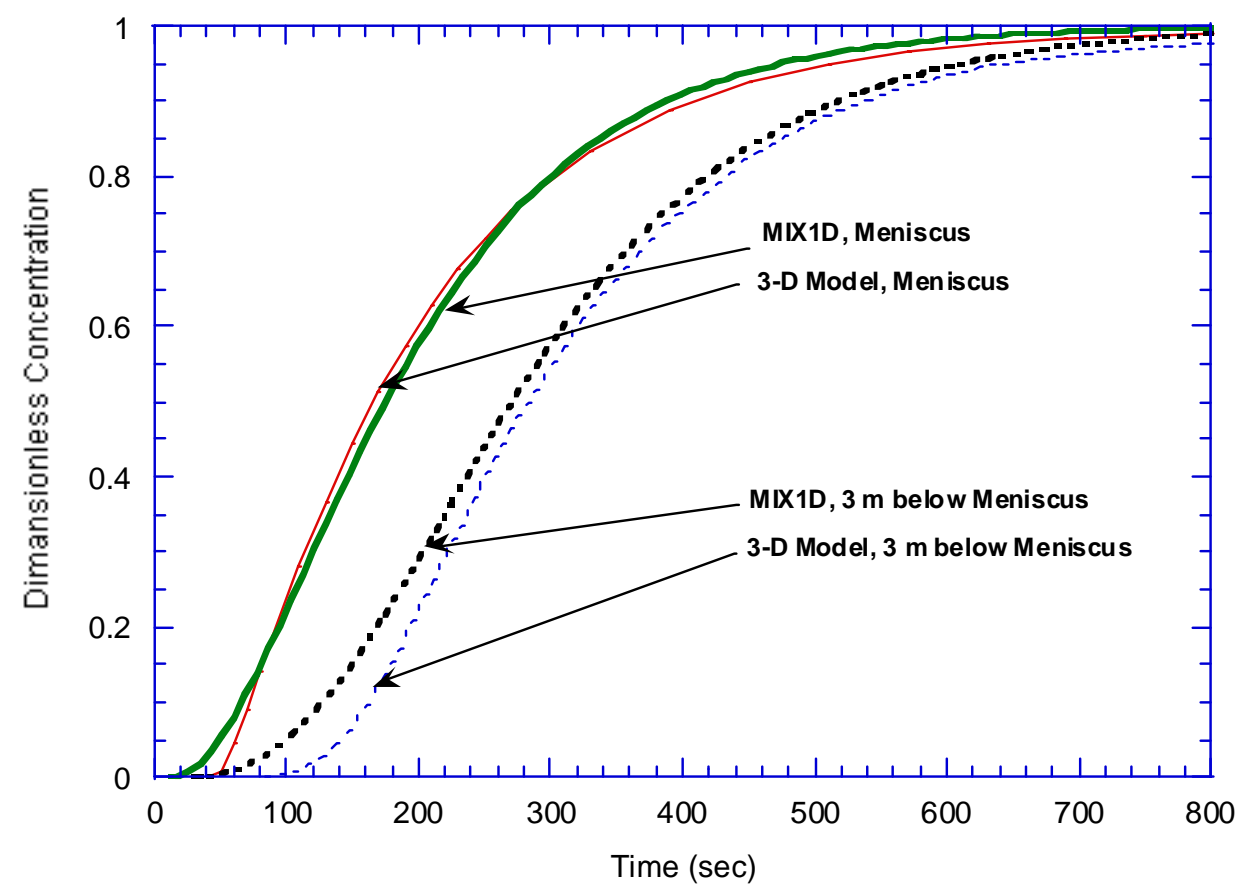

FIG. 7 Comparisons of concentration history in strand predicted by MIX1D with that by 3-D model. 


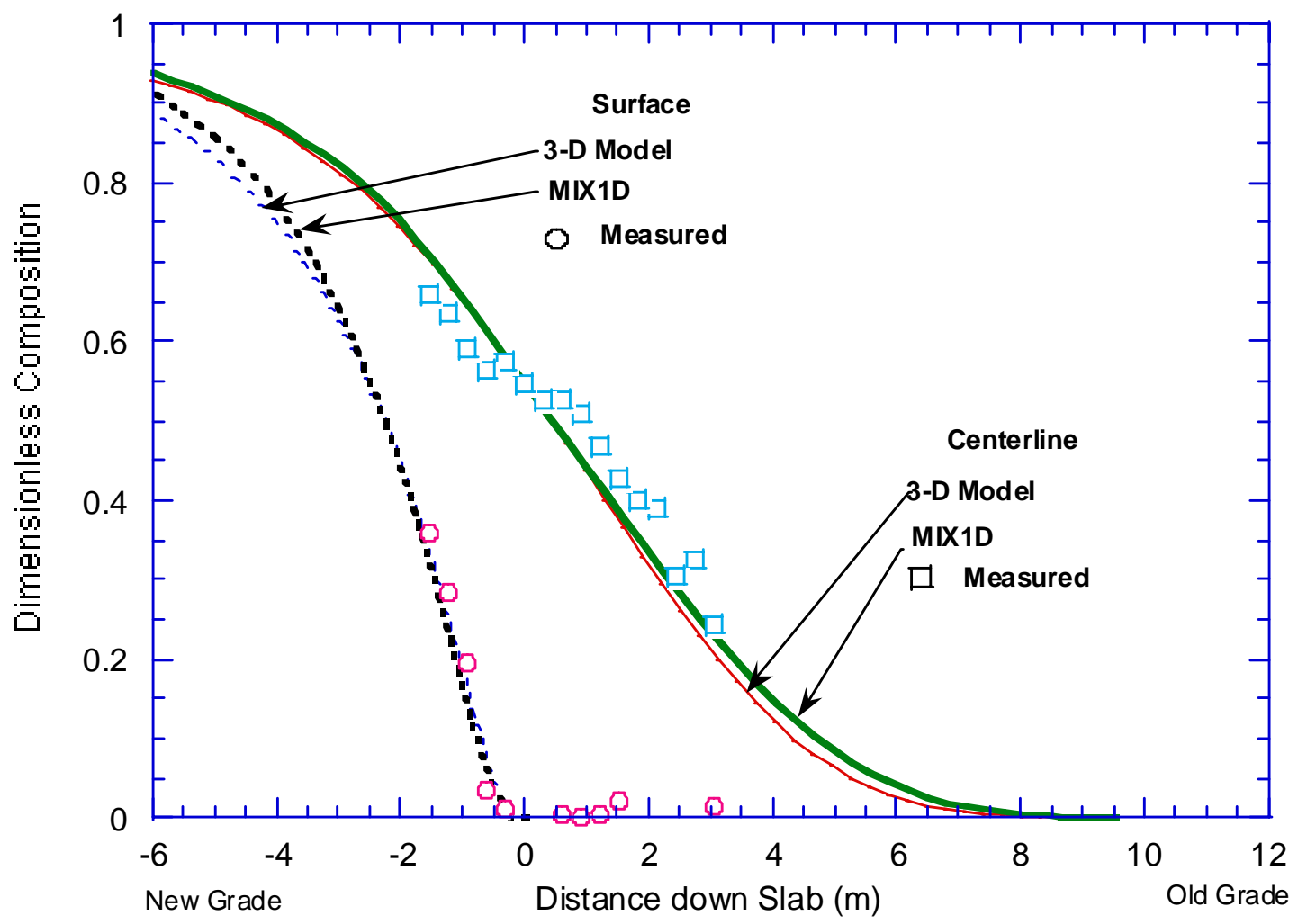

FIG. 8 Comparisons of predicted composition in the slab with the data measured at Armco[Jay]. 


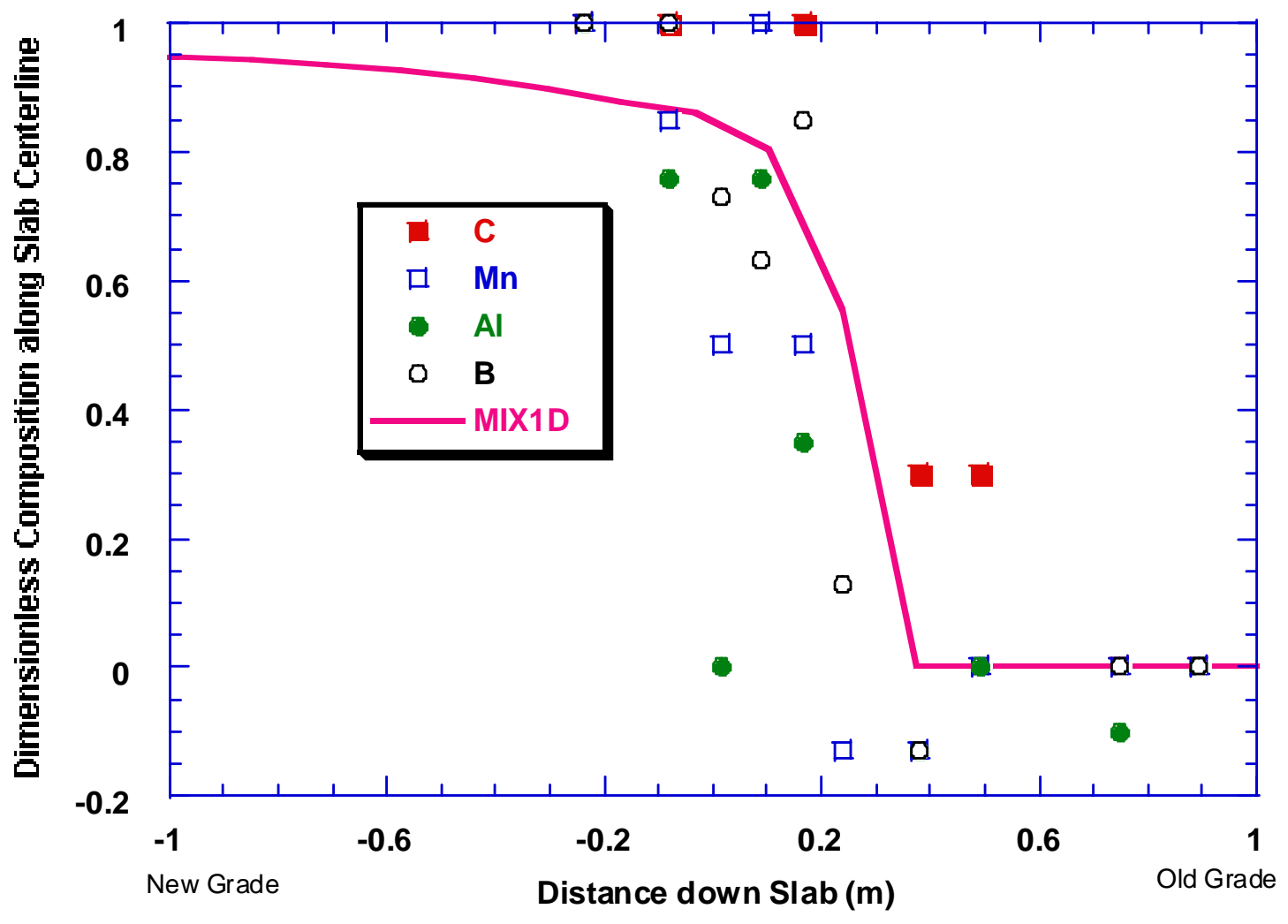

FIG. 9 Comparison of predicted slab composition with Bethlehem data (Case B in Table I) 


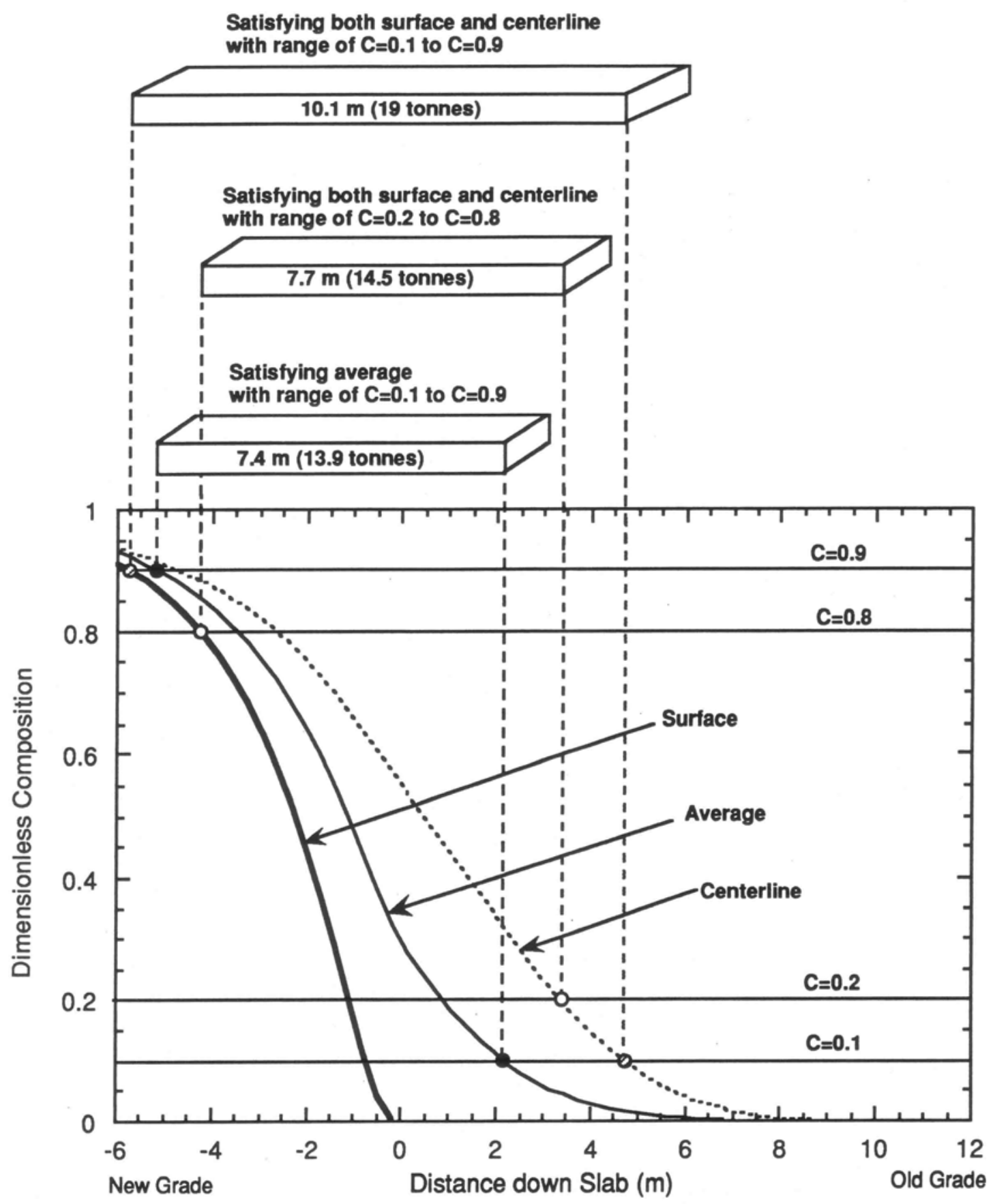

FIG 10: Typical model output of MIX1D. 


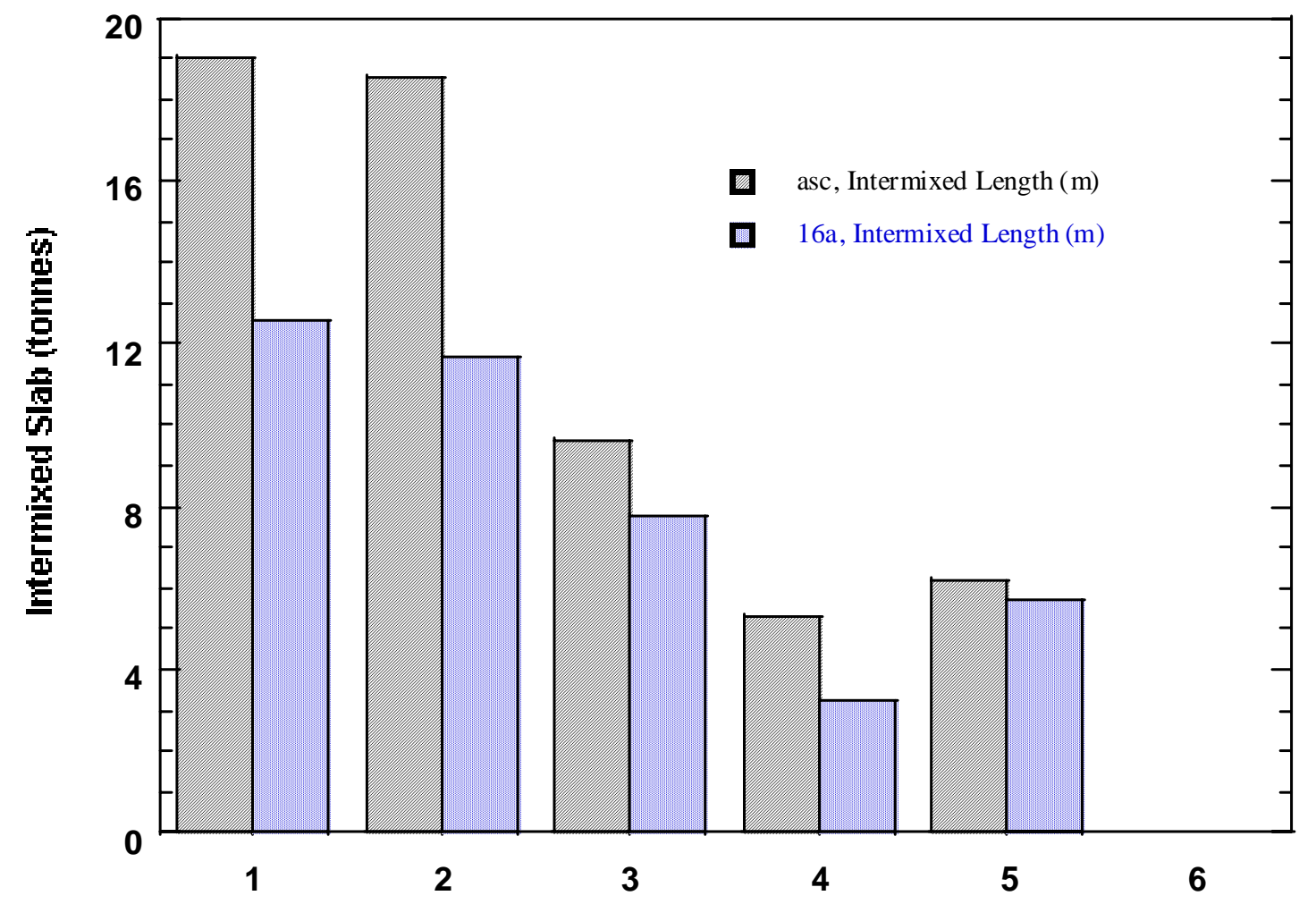

FIG. 11 Effect of tundish mixing and grade separator on intermixed slab length 


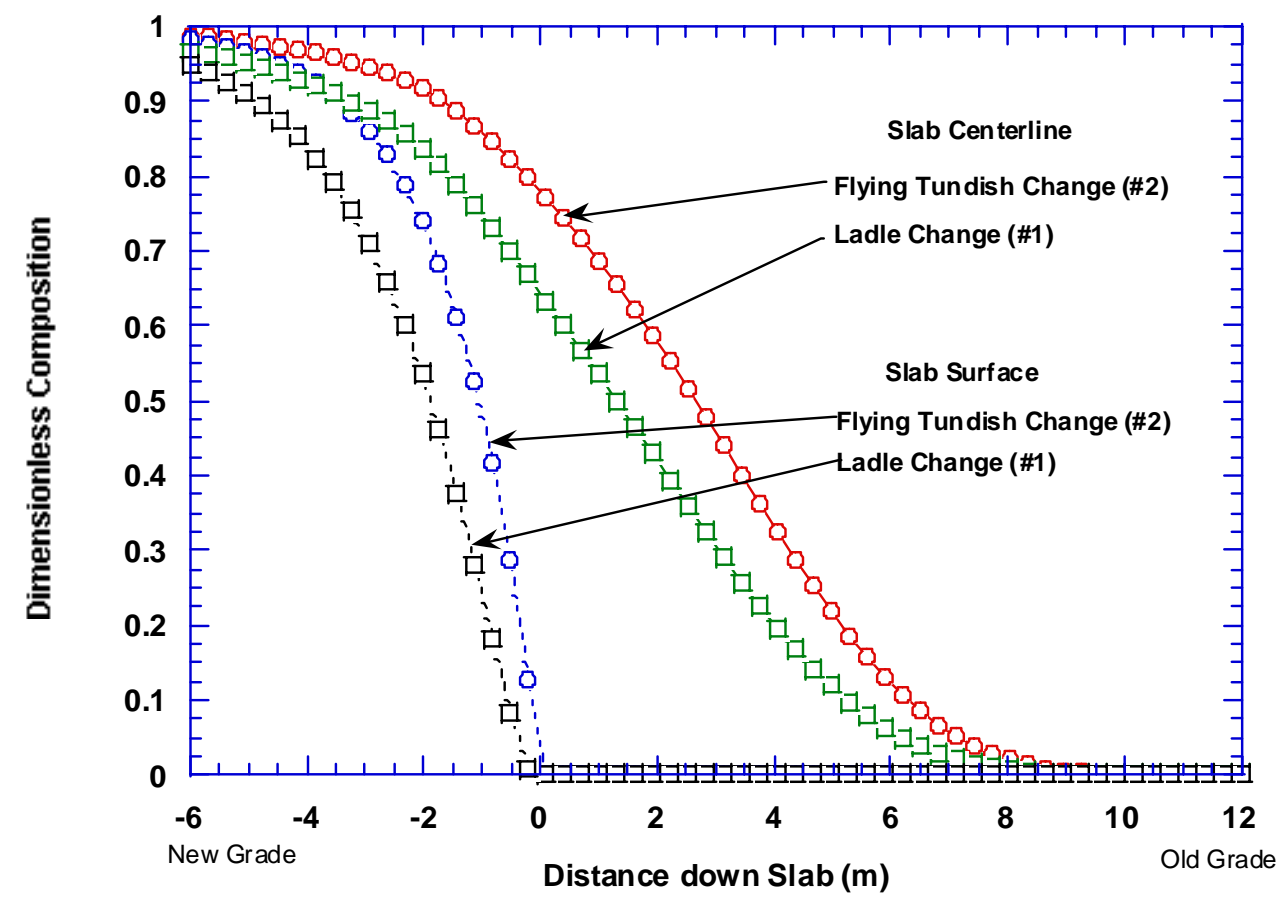

FIG. 12 Effect of tundish mixing on slab centerline and surface compositions (without separator). 


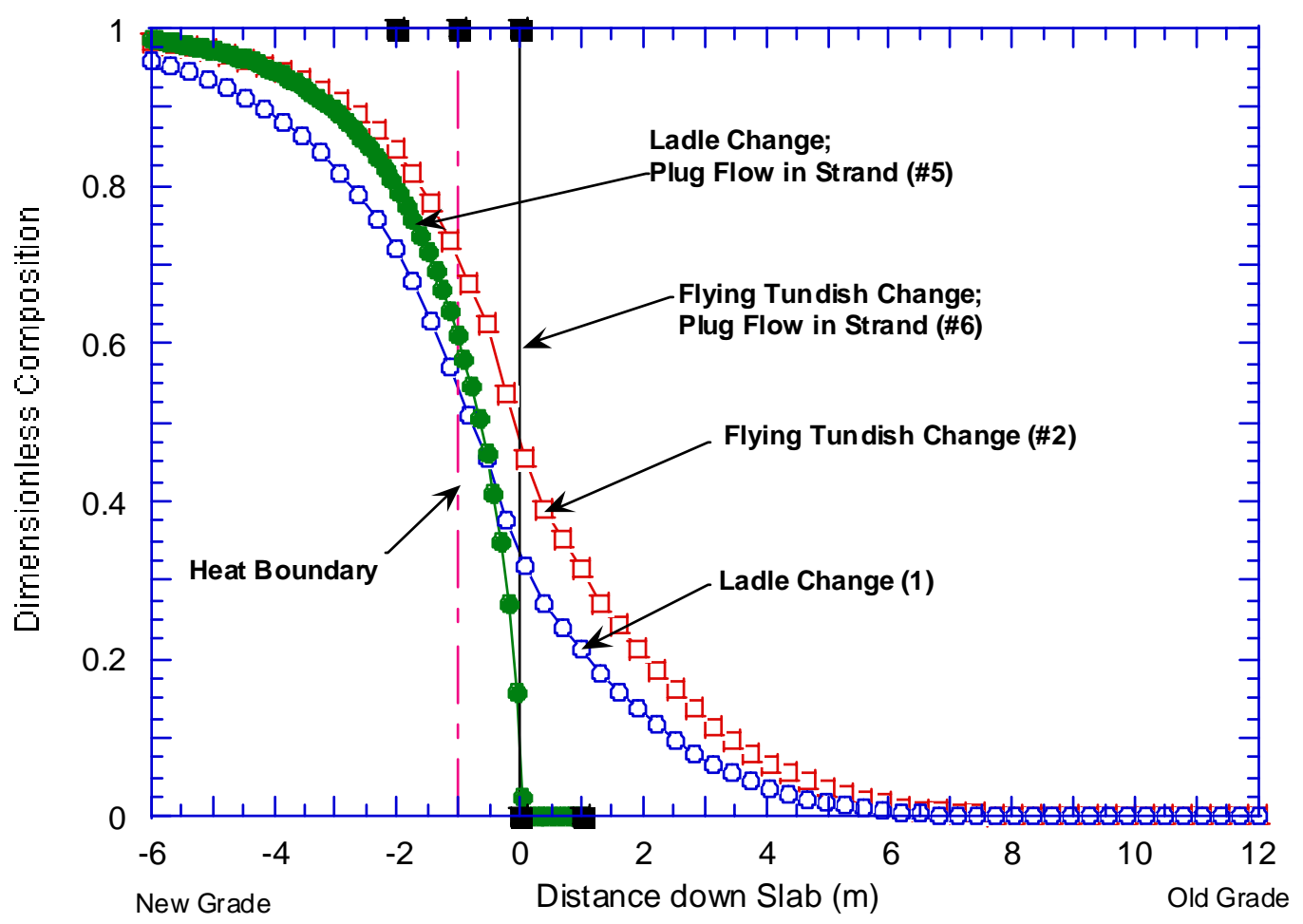

FIG. 13 Effect of tundish and strand mixing on compositions averaged across slab thickness. 


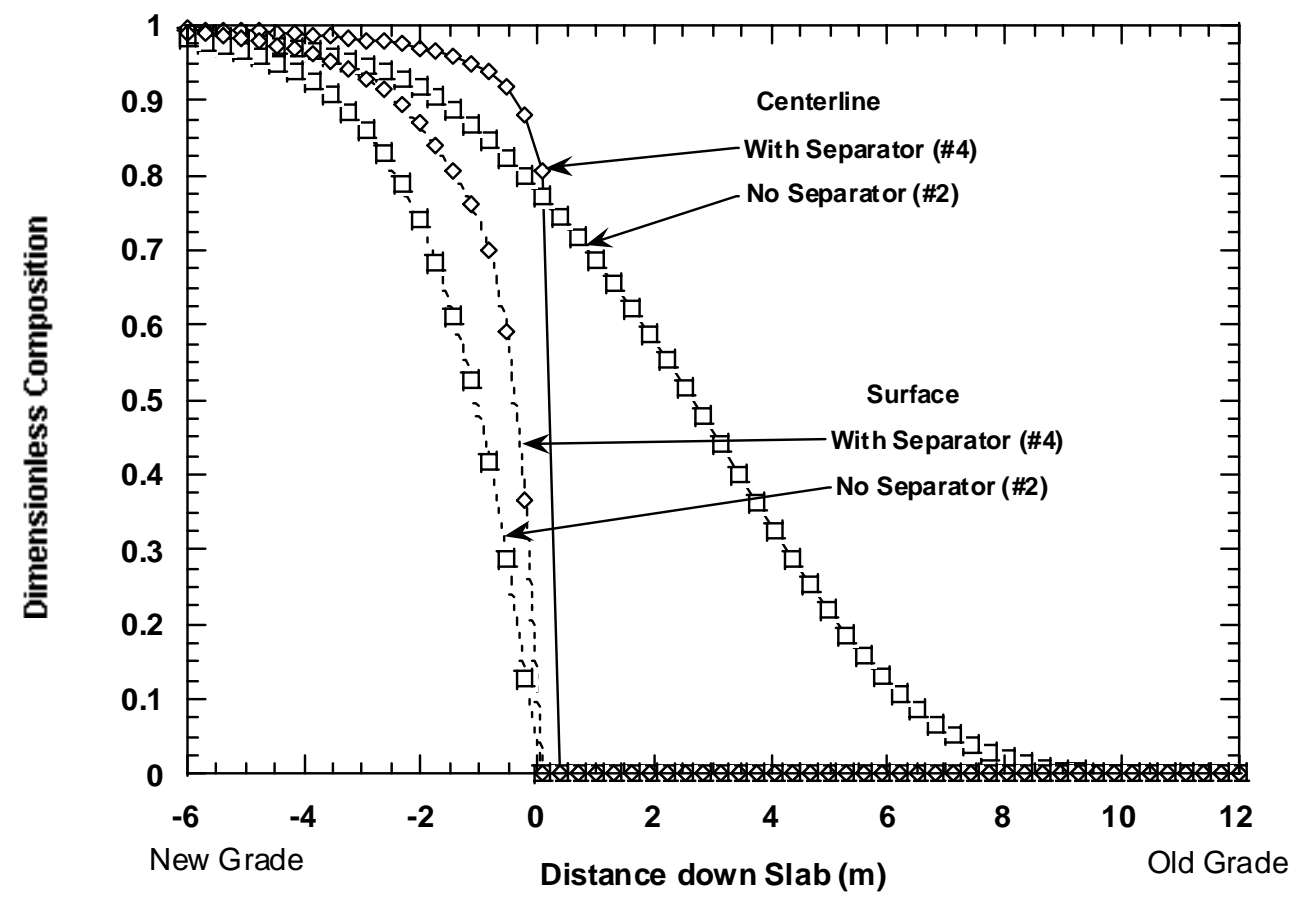

FIG. 14 Effect of grade separator on compositions of slab centerline and surface 


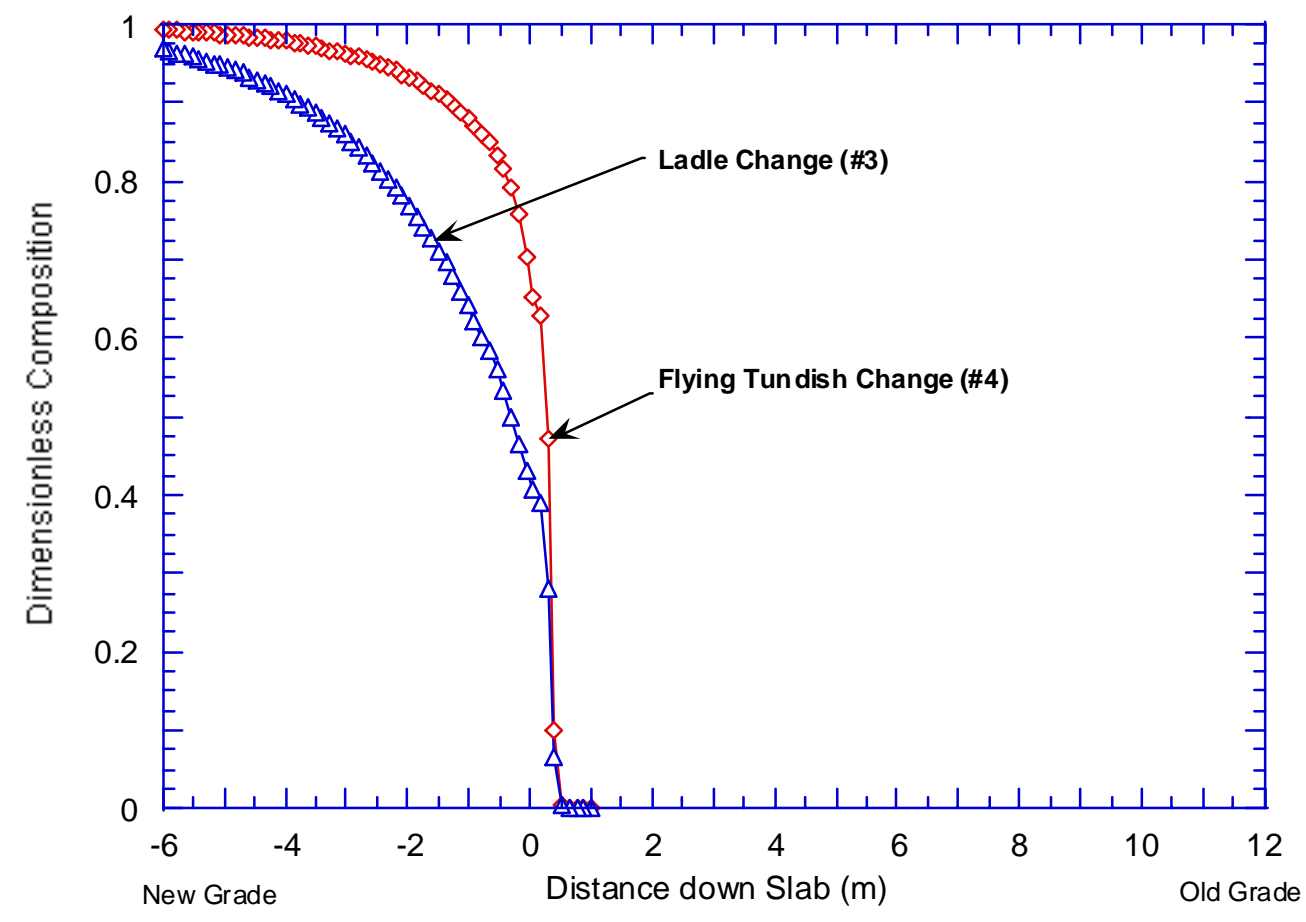

FIG. 15 Effect of tundish mixing on slab averaged compositions with a separator plate. 